\title{
Multi-scale interaction processes modulate the population response of a benthic species to global warming
}

\author{
Thomas Yoann ${ }^{1,}{ }^{*}$, Rakoto Razafimahefa Ntsoa ${ }^{2}$, Ménesguen Alain ${ }^{2}$, Bacher Cedric ${ }^{2}$
}

1 Univ Brest, CNRS, IRD, Ifremer, LEMAR, F-29280 Plouzané, France

2 Ifremer, DYNECO, Centre Ifremer de Brest, 29280 Plouzané, France

*Corresponding author : Yoann Thomas, email address : yoann.thomas@ird.fr

\begin{abstract}
:
Marine organisms are currently experiencing an unprecedented rate of climatic warming, which affects their biogeography and threatens marine ecosystem integrity. To understand how benthic species will respond to ongoing seawater warming, we assessed the relative importance of processes acting at different scales using an individual-based modelling approach. Our model integrates: (1) at the individual scale, interactions between the environment, metabolism and ontogenic transitions; (2) at the habitat scale, competition for space at settlement and mortality; and (3) at the regional scale, larval dispersal and connectivity between habitats. We focused on a coastal area in the North-East Atlantic that has experienced a significant seawater warming trend over recent decades. We built and ran a population dynamics model for the blue mussel (Mytilus edulis) in this area, which is a known biogeographic boundary zone. We then compared the response for a reference scenario and a RCP8.5 temperature projection for 2100 . We found that (1) increase in seawater temperature would result in a decrease in average biomass associated with a change in recruitment phenology; (2) response to seawater warming is not spatially homogeneous, showing the importance of processes at the habitat scale; (3) connectivity clearly limits the consequences of warming compared with other regulation processes; and (4) larval supply does not seem to be a limiting factor regulating population biomass. The use of such generic models would therefore be very valuable for guiding and optimizing research efforts and supporting the implementation of management and conservation measures.
\end{abstract}

Keywords: Individual-based modelling, Climate scenario, Connectivity, Dynamic Energy Budget, Mussel, Habitat, Biogeography, ODD 


\section{INTRODUCTION}

In the domain of macroecology, process-based models are used to predict species invasion rate, the effect of environmental changes on species distribution, and impact of management measures on species persistence (Dormann et al., 2012). In contrast to the more popular 
correlative models (also known as species distribution models or ecological niche models), process-based models are built based on explicitly stated mechanisms, a priori mathematical formulation and parameters with ecological meaning (Dormann et al., 2012). Kearney (2006) even judges that only models considering the mechanistic interactions between organisms and their environments can allow us to assess consequences in terms of fitness and should thus be considered as 'niche models'. With this aim in mind, Kearney et al. (2010) highlighted the rationale of several theoretical mechanistic frameworks including Dynamic Energy Budget (DEB) theory. DEB theory explains how organisms use energy and matter throughout their life cycles. It has been widely used to simulate the life cycles of benthic organisms, and some recent studies have used it to assess the consequences of climate change for bivalves (Montalto et al., 2016; Thomas et al., 2016b; Thomas and Bacher, 2018, Steeve et al., 2018).

In most studies modelling the response to environmental and climatic conditions, consequences are first analysed at the individual level. However, more properties would more likely emerge by upscaling from individual to population levels (Thomas and Bacher, 2018). Modelling three bivalve species with temperature scenarios using DEB approach, we have already shown that these different benthic species would experience significant and contrasting change in population growth potential under the seawater warming conditions expected in the NE Atlantic if greenhouse gas emissions continue to increase (Thomas and Bacher, 2018). We also acknowledged that more realistic models should integrate processes regulating population density, spatial interactions (e.g., larval dispersal and competition for space) and mortality at all stages of the life cycle (e.g., ageing, starvation, predation). Such a modelling framework exists and usually combines individual growth and reproduction, larval dispersal through the hydrodynamic forces, mortality and competition for space, but the coupling among all these processes has received only a little attention (Guizien et al., 2014, 2012; Le Goff et al., 2017; Ménesguen et al., 2018; North et al., 2010; Opaluch et al., 2009; Puckett and Eggleston, 2016). 
Most often, the dispersion capacity of populations has been studied as a distinct process (Coscia et al., 2013; Davies et al., 2014; Gilg et al., 2014; Haase et al., 2012; Hubbard and Reidenbach, 2015; Kim et al., 2013; Lal et al., 2016; Laugen et al., 2015; Nicolle et al., 2013; Thomas et al., 2016; Zhang et al., 2015). For instance, Lett et al. (2010) stressed the impact of climate on the dispersal and connectivity of marine populations through changes in water circulation, earlier spawning of adults, shorter durations or the pelagic larval stage, reduced exposure of larvae to lethal temperatures, shorter larval life and increased larval swimming speed. They called for integrated biophysical models including transport, growth, behaviour, mortality and larval settlement, in an environment for which both biotic and abiotic aspects are considered.

Since individual traits and interactions between individuals drive the dynamics of populations, Individual-Based Models (IBM) are useful tools making it possible to study how system-level properties emerge from the behaviour of individuals and how the system affects individuals (Grimm et al., 2006). IBM represent individual organisms as entities that differ from each other and change over their life cycles (Martin et al., 2012). They are characterized by a set of state variables and attributes that change over time and interact with their abiotic environment (e.g. habitat structure or environmental drivers such as temperature) and with each other (Martin et al., 2012). The recent work by Malishev et al. (2018) illustrates how combining DEB and IBM modelling frameworks allows individual behavioural strategies to be compared among different habitat types.

In the present study, we used an individual-based population model of a marine benthic species to explore how interaction processes operating at different spatial scales would likely modulate the response to heat stress associated with global warming. At the individual scale, the environment (i.e. temperature, food, inorganic material), individual metabolism (i.e. development, growth, reproduction efficiency) and ontogenic transition (i.e. reproductive 
phenology) interactions are formulated within Dynamic Energy Budget theory. At the local scale, individuals of benthic species compete for space during their settlement phase. Larval dispersal and the subsequent connectivity between habitats control the expansion of the population at the regional scale of the study area.

Our study focuses on the blue mussel Mytilus edulis in a coastal area if the North-East Atlantic, bordering the Western English Channel, Iroise Sea and Bay of Biscay to the south. This area is known as a biogeographic boundary zone, with both boreal/cold temperate and warm temperate marine faunal assemblages (Jolly et al., 2004; Southward et al., 2004). Like most marine ecosystems, this area has experienced a significant seawater warming trend over recent decades (Dye et al., 2013; L’Hévéder et al., 2017; Saulquin and Gohin, 2010). This warming is expected to continue in coming decades, with an annual mean sea surface temperature (SST) increase of $0.5^{\circ} \mathrm{C}$ to $2.5^{\circ} \mathrm{C}$ by the year 2100 depending on the representative concentration pathway (RCP) scenario (L’Hévéder et al., 2017). Some consequences of warming have already been identified, including warm water species becoming more common (Hawkins et al., 2008; Southward et al., 2004). Projections indicate that the distribution ranges of species are likely to change significantly, particularly for benthic species, which are unable to escape unfavourable conditions (Fly et al., 2015; Hawkins et al., 2009; Hilbish et al., 2012; Thomas and Bacher, 2018).

To predict the effect of temperature change with our integrated population model, we compared a reference scenario with the RCP8.5 climate scenario and simulated the response of populations at the regional scale of the study area. We made a detailed examination of the effect of warming on model endpoints (e.g. biomass, size structure, phenology). We also examined whether local density regulation (i.e. mortality, recruitment potential, competition for space) and connectivity would affect the response to warming. 


\section{MATERIALS AND METHODS}

\subsection{Model description}

The following sections are based on the framework of the Overview, Design concepts and Details (ODD) protocol, which is a standard way to describe an individual-based model (IBM) that makes writing and reading model descriptions more efficient, complete and easier to replicate (Grimm et al., 2010).

\subsubsection{Purpose of the model}

The purpose of the present model was to evaluate how processes associated with multi-scale interactions (from sub-individual to geographical scales) can modify the response of a bivalve species to a climate warming scenario in rocky-shore habitats along $700 \mathrm{~km}$ of coastline in the NE Atlantic. The model takes into account metabolic processes at the individual scale through Dynamic Energy Budget (DEB) theory (Kooijman, 2010). It includes a population dynamics module accounting for the spatial connectivity process between habitats at the regional scale of the study area and a submodel of biotic interactions (intraspecific competition for space) during the settlement phase at the local scale of habitat patches (Fig. 1; details given in the following sections). The model was implemented with an agent-based modelling platform: NetLogo 6.1.0 (https://ccl.northwestern.edu/netlogo/). 


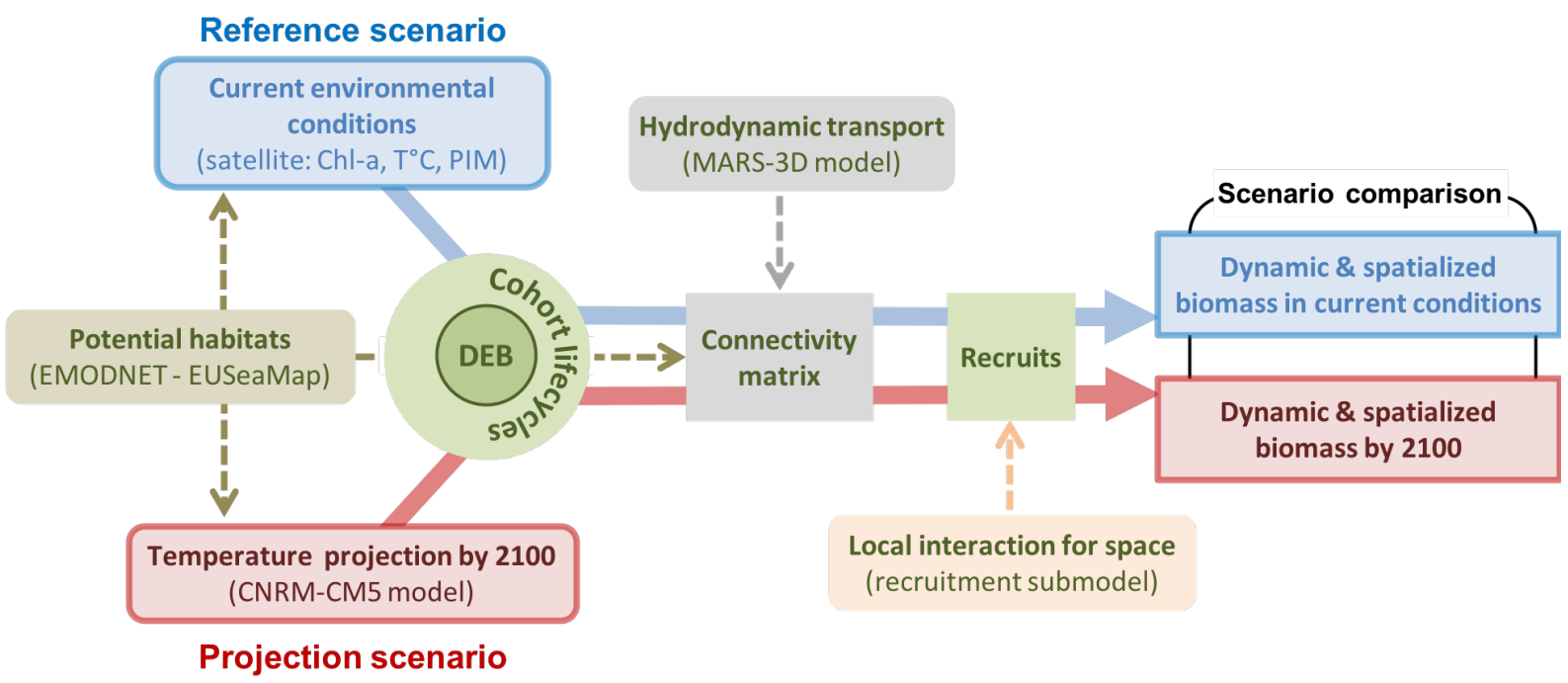

Fig. 1. Conceptual diagram of the modelling strategy. Reference and projection scenarios of current (blue arrow) and projected (red arrow) temperatures are compared. Biomass in potential habitats is simulated considering (1) individual metabolism with the Dynamic Energy Budget (DEB) model, (2) modelling of multiple cohorts, and (3) spatial interactions with connectivity at the regional scale of the study area and competition for space at the local scale of a habitat patch. Chl-a and PIM for the projection scenario are the same as in the reference scenario.

\subsubsection{State variables and scales}

We applied the model to the population dynamics of a single species, the blue mussel (Mytilus edulis, Linnaeus, 1758). The model simulates two entities: habitat patches and cohorts, which group individuals (Fig. 2). A regional patch network defines the geographical distribution of potential habitats in the study area. Each patch is a square space defined by its latitude, longitude, total area, proportion of suitable habitat for the species studied and environmental variables which represent the living conditions of the organisms. The model comprises a set of patches along the coasts of Brittany (France) (Fig. 3.a-b). We used the EUSeaMap broad-scale seabed habitat map to locate habitats and define the proportion of suitable habitat within each model patch, (http://www.emodnet.eu/seabed-habitats). EUSeaMap aims to map benthic habitats of European waters and provides access to detailed mapping of the habitats ( $250 \mathrm{~m}$ spatial resolution). Habitats are classified on the basis of seabed substrate, biological zone and hydrodynamic energy. The choice of potential habitats for mussels was based on sectors belonging to the categories 'infralittoral' and 'rock and other hard 
substrata'. For our study, patches with potential mussel habitats were considered, from the south to the north of Brittany (Fig. 3.b). All the patches are connected, allowing the transport of larvae among patches at every spawning event (Fig. S1.b). The number of larvae transported will depend on the number of cohorts reproducing, their reproductive efficiency, and the connectivity level between the emitting and the receiving patches.

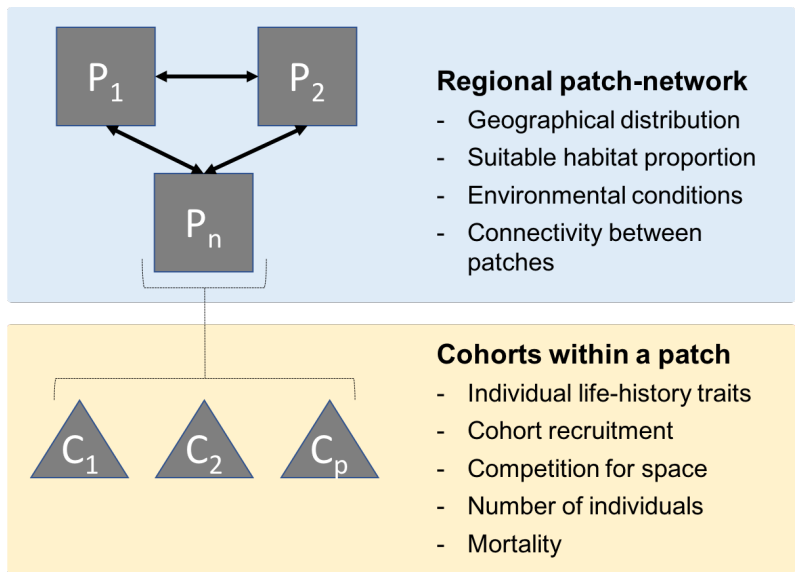

Fig. 2. Schematic diagram of the simulated entities in the mussel population model, indicating the relations between network, patch and cohort and the characteristics of each.

A cohort represents a set of individuals recruited at the same time and consequently with the same life history traits simulated by the DEB model (see section 3.1.4 'submodels'). A cohort can be thought of as a super-individual (Scheffer et al., 1995) living in a patch. Each patch can contain several cohorts and, for a given cohort, three state variables are simulated: the number of individuals, the physical length of these individuals and their reproductive state (i.e. gonadosomatic index, fecundity). Secondary variables, i.e. biomass, density, spatial coverage, recruitment, etc., are computed from these state variables at the scale of the cohort.

The patch, is the spatial unit of the model, a $4 \times 4 \mathrm{~km}^{2}$ square corresponding to the spatial element of the hydrodynamic model MARS3D (Lazure and Dumas, 2008) used to compute connectivity in the present study (see section 3.2). The results (i.e. biomass, density) are 
considered homogeneous at the scale of the model's patches and expressed in a reference unit of $1 \mathrm{~m}^{2}$. The model proceeds in discrete daily time steps.

(a)

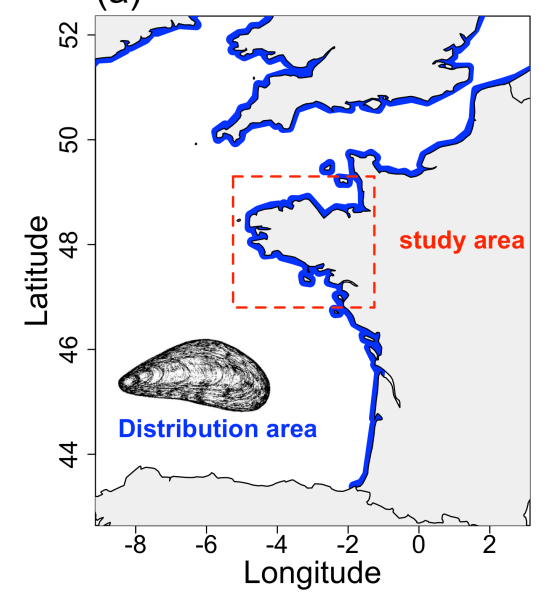

(b)

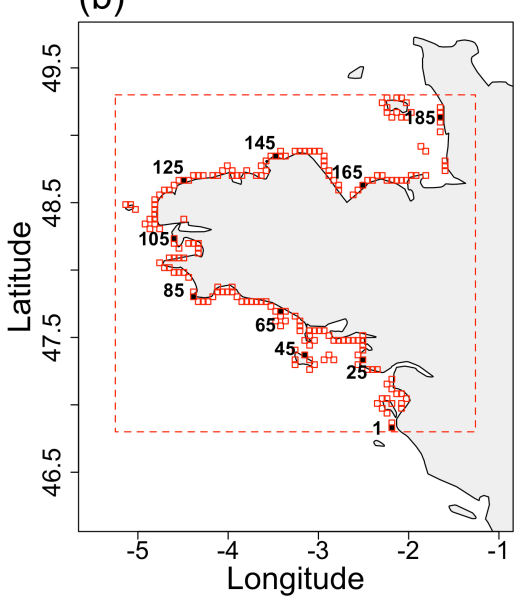

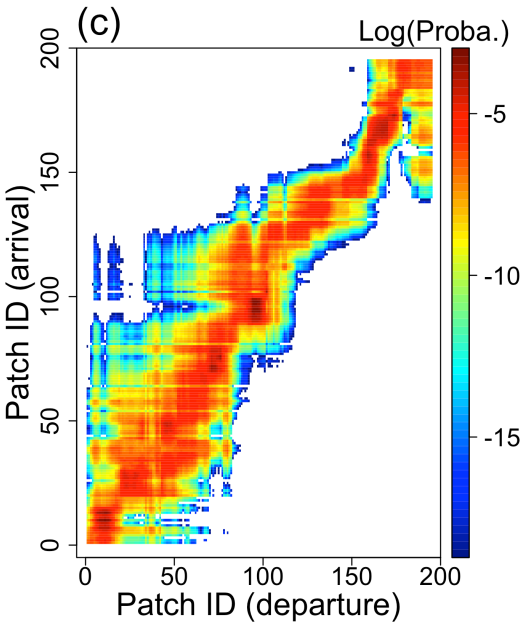

Fig. 3. Geographical information: (a) map of the mussel distribution area (blue line along the coast) and location of the study area, (b) location of the potential habitats in the study area, and (c) connectivity matrix giving the connection probability between emitting ( $\mathrm{X}$ axis) and receiving ( $\mathrm{Y}$ axis) habitat (Log scale).

\subsubsection{Process overview and scheduling}

A conceptual scheme of the model's processes is given in Figure S2. At each daily time step, the individual life-history traits (growth, maturation, reproduction) of each cohort in a given patch are simulated by the DEB model and depend on environmental forcing. If the individuals are not mature, they remain in the juvenile phase and therefore continue to grow and develop but cannot reproduce. A daily mortality rate is applied to integrate all the losses occurring during juvenile and adult phases. Reproductive phenology depends on environmental conditions and may vary greatly at the regional scale of the study area. Thus, during the adult stage, spawning events are triggered when two thresholds are concurrently reached: a seawater temperature and a gameto-somatic index (GSI) threshold of 35\%. GSI is defined as the mass ratio between the gametes and total dry flesh mass. Since low and high temperatures may inhibit reproduction (Fearman and Moltschaniwskyj, 2010; Lubet, 1959; Shpigel et al., 1992), lower and higher temperature thresholds inhibiting spawning were also defined $\left(\mathrm{TL}_{\mathrm{spw}}=10^{\circ} \mathrm{C}\right.$ and 
$\mathrm{TH}_{\text {spw }}=17^{\circ} \mathrm{C}$ ). Outside of this range, individuals continue to grow and to acquire energy for the development of gametes.

When spawning occurs within a habitat patch, the total number of larvae produced is calculated based on the individual fecundity and the number of individuals releasing gametes. A mortality rate is then applied to integrate all the losses occurring during the larval phase. The connectivity matrix then makes it possible to evaluate the proportion of the larvae produced that will be exported to other patches and the proportion that will remain in the starting patch (self-recruitment). The larval phase is not explicitly simulated, spawning and recruitment can occur at the same time step and new recruits all have the same initial properties. However, for the purposes of modelling, individuals recruited within a given temporal window are grouped into a single new cohort (see Section 3.1.4.2). Within each patch receiving larvae, if enough space is available, we enter into the recruitment process. A given number of recruits will settle according to the available space. Recruitment results in the creation of a new cohort, with an initial number of individuals equal to the number of recruits that can settle.

At each time step, the age and the number of individuals in each cohort, total number of individuals in a habitat patch and total space occupied in each patch are simultaneously updated and recorded.

\subsubsection{Submodels}

\subsubsection{Dynamic Energy Budget (DEB)}

Dynamic Energy Budget (DEB) theory offers a quantitative framework (i.e. mass and energy) to model metabolic fluxes at the individual scale. These fluxes modulate substrate uptake and use and sustain life-history trait dynamics: growth rate, life-stage transitions, reproductive output and mortality (Kooijman, 2010). The DEB model follows the complete life cycle of one individual from the embryo to juvenile and adult stages. An individual is defined 
by four state variables: reserves $(E$, unit: $\mathrm{J})$, structure $\left(V\right.$, unit: $\left.\mathrm{cm}^{3}\right)$, maturity $\left(E_{H}\right.$, unit: J), and reproduction $\left(E_{R}\right.$, unit: J); and seven metabolic processes (unit: J.day $\left.{ }^{-1}\right)$ : ingestion $\left(\dot{p}_{X}\right)$, assimilation $\left(\dot{p}_{A}\right)$, reserve mobilization $\left(\dot{p}_{C}\right)$, growth $\left(\dot{p}_{G}\right)$, somatic maintenance $\left(\dot{p}_{M}\right)$, maturity maintenance $\left(\dot{p}_{J}\right)$, maturation and reproduction $\left(\dot{p}_{R}\right)$. Life-stage successions are linked to maturity thresholds. The transition between embryo and juvenile occurs when $E_{H}=E_{H}^{b}$, and the transition between juvenile and adult occurs when allocation to reproduction occurs coupled with the cessation of maturation, when $E_{H}=E_{H}^{p}$. Somatic maintenance has priority over growth, and maturity maintenance has priority over maturation or reproduction. Details on DEB model equations and parameter values are given in the supplementary materials (Table S1 and Table S2). The individual life-history traits extracted from the DEB model were the individual physical length $(L, \mathrm{~cm})$, total mass $(W, \mathrm{~g})$ and fecundity $(F$, number of eggs produced). We assumed the same parameter values for males and females. DEB parameters for mussel were derived from the literature (Saraiva et al., 2012; Thomas and Bacher, 2018) (Table S2).

Two forcing variables, temperature and food density, modulate metabolic rates and drive individual growth and reproduction in the DEB model. When exposed to high concentrations of suspended particulate inorganic matter (PIM), bivalves maximize organic ingestion through pseudo-faeces production. We therefore introduced PIM concentration as a third forcing variable, related to the ingestion functional response $(f \in[0,1])$, following Kooijman's (2006) conceptualization:

$$
f=\frac{X}{X+K\left(1+\frac{Y}{K_{Y}}\right)}
$$

where $X$ is the food density, $Y$ the PIM concentration, $K$ the half saturation coefficient related to food density and $K_{Y}$ the half saturation related to inorganic matter concentration. For bivalve species ingestion rate, the half saturation coefficient of the functional response is known to change as a function of the food quantity and/or quality and species physiological flexibility 
(i.e. particle selection capacity) (Alunno-Bruscia et al., 2011). In the present study, a linear relationship between the mean Chl-a concentration and the half saturation parameter $(K)$ was calibrated for mussel in order to take into account feeding adaptation to local conditions (see Thomas and Bacher, 2018, for calibration and validation steps performed on several datasets extracted over a wide latitudinal gradient).

In the DEB model, seawater temperature acts on metabolic rates following the Arrhenius function, extended over the species tolerance range, based on the idea that metabolic rates are controlled by enzymes that are inactive beyond the optimal temperature range (Kooijman, 2010), and giving a temperature correction factor $\left(T_{C}\right)$ :

$$
\begin{aligned}
T_{C}=\exp \left\{\frac{T_{A}}{T_{1}}-\frac{T_{A}}{T}\right\} \\
\cdot\left(1+\exp \left\{\frac{T_{A L}}{T_{1}}-\frac{T_{A L}}{T_{L}}\right\}+\exp \left\{\frac{T_{A H}}{T_{H}}-\frac{T_{A H}}{T_{1}}\right\}\right) \\
\cdot\left(1+\exp \left\{\frac{T_{A L}}{T}-\frac{T_{A L}}{T_{L}}\right\}+\exp \left\{\frac{T_{A H}}{T_{H}}-\frac{T_{A H}}{T}\right\}\right)^{-1}
\end{aligned}
$$

where $T$ is the actual temperature, $T_{A}$ the Arrhenius temperature in the tolerance range, $T_{1}$ the reference temperature $\left(20^{\circ} \mathrm{C}\right)$ for which $T_{C}=1, T_{L}$ and $T_{H}$ are the lower and higher boundaries of the optimal tolerance range and $T_{A L}$ and $T_{A H}$ the Arrhenius temperatures beyond the lower and higher boundaries, respectively.

\subsubsection{Recruitment submodel}

At the local scale of a patch, the settlement submodel makes it possible to integrate interactions between new individuals at the time of attachment to the substrate: settlement of new recruits is only possible if there is sufficient space. If the space is limited, only a limited number of individuals settle and recruit, while the others die. If there is no space, there is no 
settlement and all individuals die. The settlement submodel integrates the spatial connectivity, which allows the inclusion of spatial interactions between patches.

The recruitment submodel is based on the work of Roughgarden et al. (1985). It also incorporates the connectivity process that allows a spatially explicit approach and integration of spatial interactions between habitat patches. Recruitment therefore involves (1) evaluating the number of larvae produced, (2) integrating the connectivity process, and (3) integrating small-scale spatial interactions (intra-specific competition for space). These processes are defined in the following sections below.

\section{Larval production}

When a spawning event occurs, at time $(t)$, the number of eggs produced in a patch $i\left(O_{i}(t)\right.$, \# number of eggs) is the cumulative number of eggs produced by the $n$ cohorts:

$$
O_{i}(t)=\sum_{c=1}^{n} S R F_{c i} N_{c i}(t)
$$

where $S R$ corresponds to the population sex ratio, $F_{c i}$ the number of eggs produced by an individual of the cohort $c$ in patch $i$, and $N_{c i}(t)$ the number of individuals within the cohort $c$ in patch $i$ at time $(t)$. We considered an $S R$ of $50 \%$, which corresponds to the mean proportion in natural populations (Yasuoka and Yusa, 2016; Yusa et al., 2013). The produced egg number is then adjusted by a mortality rate $(\mathrm{m})$, including the overall mortality during the larval phase (i.e. fertilization success $(F S)$ and daily mortality rate $\left(M_{\text {larvae }}\right)$ associated with the pelagic larval duration $(P L D))$. This rate is assumed to be constant and spatially uniform. The total number of potential recruits produced in a patch $i$ at time $t\left(l_{i}(t), \#\right.$ larvae) is:

$$
l_{i}(t)=O_{i}(t) m \text { with } m=F S e^{-M_{\text {larvae }} P L D}
$$

\section{Spatial connectivity}


The connectivity process allows the number of larvae coming from a given habitat patch to be quantified. These will then be distributed within the connected habitat patches through the larval dispersal process. The connectivity matrix synthesizes the rate of connection between every emitting habitat patch and all the others, including itself (self-recruitment). The total number of larvae received by a given patch $j$ at time $t\left(L_{j}(t)\right.$, \# larvae) corresponds to the sum of the larvae produced in the $k$ patches connected with $j$, multiplied by the connectivity rate between $j$ and each of the $k$ patches $\left(C_{i j}, \%\right)$ :

$$
L_{j}(t)=\sum_{i=1}^{k} l_{i}(t) C_{i j}
$$

where $C_{i j}$ is the connectivity rate between patches $i$ and $j$.

\section{Competition for space}

Occupancy of the substrata by sessile organisms can be represented by a 2-D physical area of each individual. Competition for space occurs at the time of recruitment. New recruits will only be able to settle if enough space is available to accommodate them. This available area is a function of the occupancy rate by all the individuals already recruited. It evolves over time depending on individuals' growth and mortality and the arrival of new recruits. The physical surface area occupied by an individual $\left(b, \mathrm{~m}^{2}\right)$ is a function of individual height $(h, \mathrm{~cm})$ and width $(l, \mathrm{~cm})$. The allometric equation for calculating the individual basal area is written:

$$
\begin{gathered}
b(t)=h(t) l(t) \\
\text { where } h(t)=\frac{L(t)}{\alpha} \text { and } l(t)=\frac{L(t)}{\beta}
\end{gathered}
$$

with allometric parameters $\alpha$ and $\beta$ linking individual height and width to the physical length $L$ (Alunno-Bruscia et al., 2001). This relation is needed because the DEB model only gives the 
physical length. The cumulative surface area occupied by all individuals within a patch $i$ $\left(B_{i}, \mathrm{~m}^{2}\right)$ is the sum of the space inhabited by all individuals of the $n$ cohorts:

$$
B_{i}(t)=\sum_{c=1}^{n} b_{c i}(t) N_{c i}(t)
$$

where $b_{c i}(t)$ is the individual surface coverage for cohort $c$ in patch $i$ at time $t$, and $N_{c i}(t)$ is the total number of individuals within the cohort $c$ in patch $i$, at time $t$. The available area for recruitment in patch $i\left(F_{i}(t)\right)$ is then obtained from:

$$
F_{i}(t)=A_{i}-B_{i}(t)
$$

where $A_{i}$ is the habitat area in patch $i$, scaled at $1 \mathrm{~m}^{2}$.

Finally, the number of recruits will depend on the area of habitat needed by a single recruit $\left(b_{0}, \mathrm{~m}^{2}\right)$, which then makes it possible to calculate the number of recruits per available surface unit $\left(s\right.$, ind. $\left.\mathrm{m}^{-2}\right)$ and to calculate the number $Q$ of recruits that can be fixed at time $(t+1)$, per unit of space:

$$
\begin{gathered}
s=\frac{1}{b_{0}} \\
Q_{i}(t+1)=s F_{i}(t)
\end{gathered}
$$

Within a habitat patch, spawning events occurring at the same time step are considered together to generate a single new cohort per patch. Thus, individuals recruited within a 22-day interval, which is the mean pelagic larval duration for mussel (Sprung, 1984), are grouped into a single new cohort.

\subsubsection{Changes in population abundance and biomass}

\section{Mortality after settlement}


The number of individuals in a given cohort $c$ and patch $i$ at time $t\left(N_{c i}(t)\right)$ is defined as follow:

$$
N_{c i}(t)=N_{c i}(0) e^{\left(-M a_{c i}(t)\right)}=Q_{c i} e^{\left(-M\left(t-t_{c i}(0)\right)\right.}
$$

where $Q_{c i}$ is the initial number of recruits for a given cohort $c$ in patch $i, M$ the daily mortality rate after settlement, $a_{c i}(t)$ the age of the cohort $c$ in patch $i$ at time $t$, and $t_{c i}(0)$ the time step when the cohort was created in patch $i$. A cohort disappears when its age $\left(a_{c}(\mathrm{t})\right.$, days) reaches the lifespan of the species ( $a_{d}$, days; Table S2). In the model, lifespan is assumed to be both constant and spatially homogeneous.

\section{Mussel biomass}

Cumulative biomass in every patch $i$ at time $(t)\left(\operatorname{Biom}_{i}(t)\right)$ is computed as follows:

$$
\operatorname{Biom}_{i}(t)=\sum_{c=1}^{n} N_{c i}(t) W_{c i}(t)
$$

where $W_{c i}(t)$ is the individual mass for individuals in cohort $c$ of patch $i$ at time $(t)$.

\subsection{Input data}

The DEB model is computed using daily time series of water surface temperature (SST), chlorophyll-a concentration (Chl-a) and particulate inorganic matter (PIM) concentration. Daily Chl-a and PIM concentration time series from 2000 to 2014 were obtained from ocean colour remote-sensing using merged SeaWiFS, MODIS and MERIS data processed using a regional algorithm specifically designed for the coastal waters of the Bay of Biscay (Gohin et al., 2002; Saulquin et al., 2011). The daily sea surface temperature (SST) was obtained from remotesensing products from the Advanced Very High Resolution Radiometer (AVHRR) over 20002008 and from the Group for High Resolution Sea Surface Temperature (GHRSST) initiative over 2009-2014 (Martin et al., 2012). Input datasets are imported in NetLogo as tables, each 
row corresponding to one time-step and each column to a patch. Time series of the individual functional response and temperatures in every patch for the reference and projection scenarios are given in Figure S3a-b.

Following the work by Thomas and Bacher (2018), two temperature scenarios were considered and compared in this study: 1) a reference (R) scenario, consisting of current temperature conditions, based on the 2000-2015 period following the above description from satellite information; and 2) a projection (P) scenario, consisting of predicted thermal conditions at the end of the $21^{\text {st }}$ century, based on the $2085-2100$ period. For the latter, we chose the well documented and most severe scenario, known as the 'business as usual' Representative Concentration Pathway scenario RCP8.5 (i.e. the rising radiative forcing pathway leading to $8.5 \mathrm{~W} \cdot \mathrm{m}^{-2}$ by 2100 ), which assumes that greenhouse gas emissions will continue to rise throughout the remainder of the $21^{\text {st }}$ century (van Vuuren et al., 2011). For every location, time series of Sea Surface Temperature (SST) were extracted from the CNRMCM5 climate model outputs (from the French National Centre for Meteorological Research's Coupled Model Intercomparison Project 5 (CMIP5) archive (https://esgf-node.llnl.gov), following the nearest neighbour strategy. This model demonstrated its ability to correctly simulate the mean present-day SST seasonal cycle in the considered area with a higher ocean resolution $\left(1^{\circ} \times 1^{\circ}\right)$ and more realistic topography and coastline geometry than other climate models (L'Hévéder et al., 2017). SST from the climate model was available with daily frequency. There is significant uncertainty in the projections of phytoplankton production by climate models. Furthermore, Thomas and Bacher (2018) showed that these projections would have a limited effect on population growth performance. Our projection simulations therefore used the same Chl-a time series as the reference scenario. Response of mussel populations along the latitudinal gradient was then studied by comparing the mean biomass per unit area between the two temperature scenarios. 
The connectivity matrix is an array with as many rows as columns, corresponding to the number of patches in the model (Fig. 3.c). Each cell in the table contains a connection rate between a emitting patch (column) and a receiving patch (line). The connectivity matrix was derived from simulations performed by a hydrodynamic model (MARS3D) that simulates the evolution of the concentrations of a tracer emitted in each potential habitat mesh square and dispersed over a period of 22 days. The emitted particles were considered to be passive, with no vertical migration behaviour considered. The mesh size of the hydrodynamic model is $4 \times 4$ $\mathrm{km}$. Computing the connectivity matrix for several decades was not possible. Connectivity simulations were thus performed monthly for a given year to represent the mean conditions encountered over a long period and maintain realistic forcing. The year 2005 was chosen after an analysis of wind conditions over 10 years, which showed that this year was the closest to the climatology of this area.

\subsection{Initialization}

At the initial time step, one single cohort with 50 ind. $\mathrm{m}^{-2}$ is created in every patch. All individuals are similar and considered to be at the post-metamorphosis stage. Time series of simulated biomass in every patch are given in Figure S3c for the reference and projection scenarios, with identification of the spin-up and analysed periods. A spin-up time of three years is long enough for the emergence of a stable pattern of abundance and biomass at the scale of the study area and was applied before analysing the model results over a period of 15 years.

\subsection{Model calibration and performance evaluation}

A set of data was extracted from the literature (Table S3) for the calibration of two parameters: the post-settlement mortality rate $(M)$ and the number of recruits per available surface unit ( $s$ ) (Fig. 4). The median was chosen because of the asymmetrical dispersion of the data. Model performances were then evaluated with these values, with regard to the simulated 
mussel density, space coverage, number of recruits 10 months post-settlement and mussel size distribution. Due to the uncertainty associated with these density control parameters, we performed a sensitivity analysis on them (see next section).

(a)

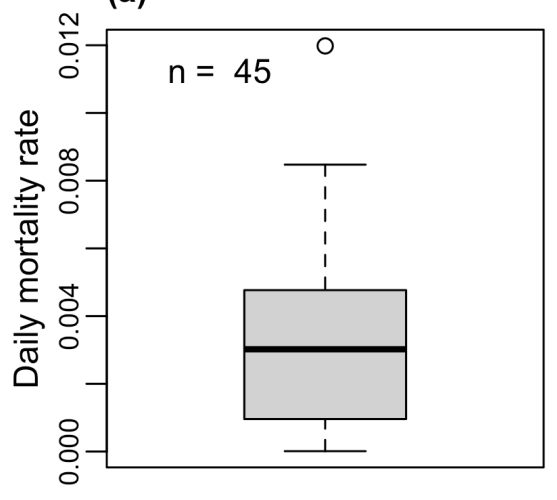

(b)

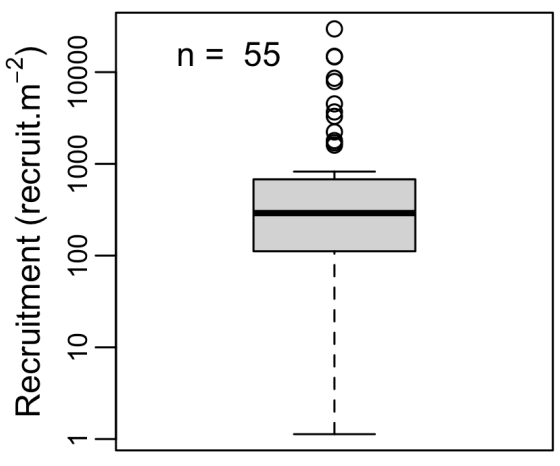

Fig. 4. Observed (a) mortality rate and (b) recruitment density used for the model calibration step. Medians were used for model parameterization: $M=0.003 \mathrm{~d}^{-1} ; s=290$ recruits. $\mathrm{m}^{-2}$.

\subsection{Sensitivity analysis}

A first step, in order to evaluate stability and potential edge effects, was to assess the effect of the spatial model fit on the results. Three zoom levels were compared, corresponding to three spatial coverages, with differences between biomass variations related to temperature scenario computed between each pair of zooms. A description of these preliminary results is given in the supplementary material (Fig. S4, Fig. S5 and associated text), and led us to choose one zoom level as the study area for the subsequent analyses.

A set of sensitivity analyses was then conducted to assess the effect of interaction processes occurring at different spatial scales on the response to the temperature scenarios. We tested the effect of the connectivity, which represents interactions occurring at the regional scale of the study area and the effect of larval and adult mortality and recruitment potential, which are related to processes occurring at the local scale of habitat patches. 
For the connectivity scenarios, the results obtained with a reference connectivity scenario (i.e. monthly connectivity, PLD $=22$ days) were compared with a scenario without connectivity, under which there was only self-recruitment, considered to be average and uniform over the whole area, corresponding to the average value of the connectivity matrix diagonal. Since temperature has the effect of shortening the duration of the pelagic larval phase, we tested a connectivity scenario with a PLD of 19 days, which reduced the dispersal potential and larval mortality. Finally, in order to assess the impact of seasonal variability in connectivity patterns associated with the reproductive phenology (i.e. seasonality of the spawning events), we compared the baseline scenario with year-averaged connectivity scenarios in each habitat for each PLD (i.e. 19 and 22 days).

For the sensitivity analysis of mortality and recruitment potential, we applied factors of \pm $10 \%$ and $\pm 50 \%$ to the mean values of larval mortality $(\mathrm{m})$, adult daily mortality rate $(M)$ and number of recruits per unit area $(s)$. We ran simulations for both temperature scenarios and compared the responses to temperature changes obtained with the modified parameter values with the results obtained with the mean values.

In every patch and at each time step, simulated values were output and stored in the form of .CSV files for (1) individual life history traits (size, weight, gonado-somatic index, spawning efficiency) for each cohort, (2) population structure (density per cohort, recruitment), and (3) habitat cover rates in all patches. All these outputs were used to perform post-treatment with $\mathrm{R}$ software (R Development Core Team, 2012). 


\section{RESULTS}

\subsection{Model performance evaluation}

Our simulated mean densities, coverage rates and recruitment observed 10 months after fixation (Fig. 5.a-b-c) are not significantly different from the observations (t-test, $\mathrm{p}<0.05)$. The simulated mean size distribution at the patch scale matches the mean size distribution produced by a set of observations (Fig. 5.d). The variance measured in the observations is well reproduced by the simulated monthly profiles, which show the evolution of mussel sizes distribution over the year as a result of recruitment, growth and mortality processes. Simulated maximum lengths around $8 \mathrm{~cm}$ are consistent with observed data, although the $4 \mathrm{~cm}$ class appears underestimated and the $6 \mathrm{~cm}$ class overestimated by the model.
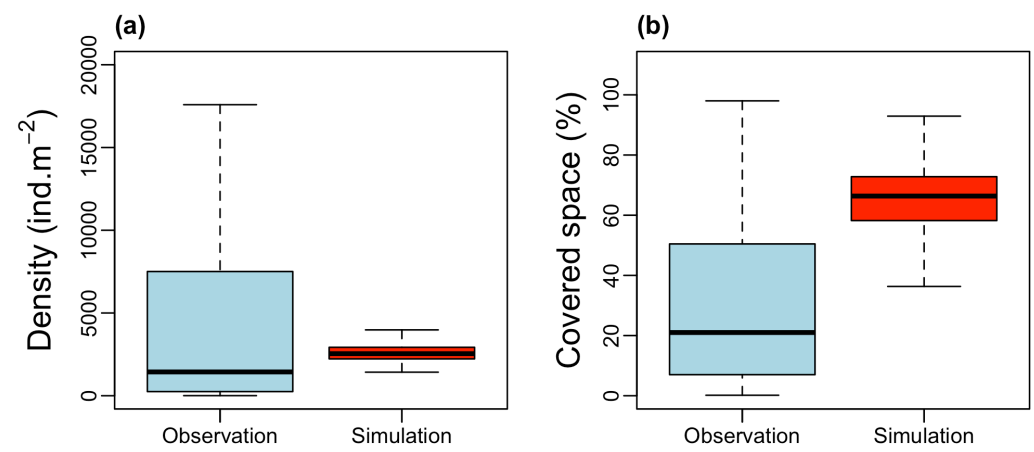

(c)
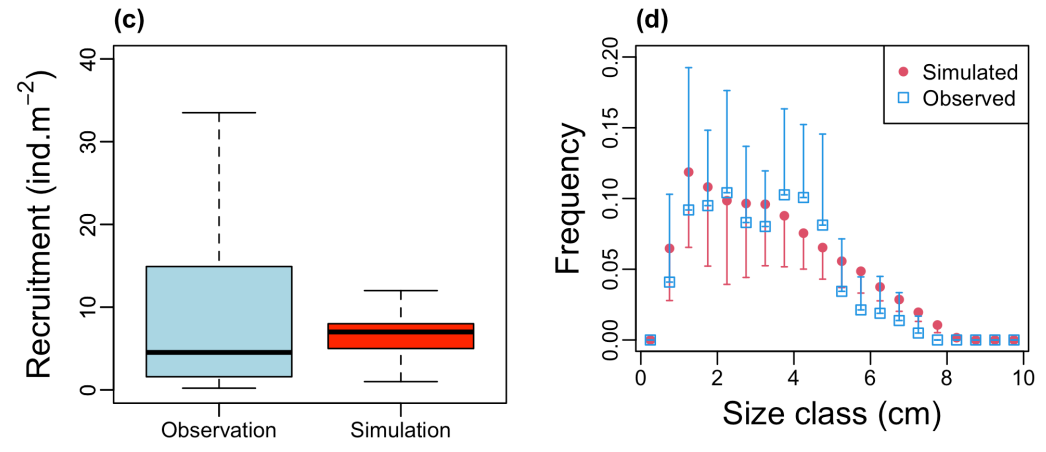

Fig. 5. Comparisons of the IBM predictions with data from the literature. (a) Observed density (n $=71)$, $(b)$ covered area $(n=37)$ and $(c)$ recruitment density after 10 months $(n=53)$. No significant differences were found between observations and simulations (Student test, $p<0.05$ ). (d) Individual size (i.e. length) distributions: observations refer to a set of published data (mean \pm STD; see Table S3) and simulations to the monthly average distributions for all patches, error bars represent the monthly variability (i.e. STD; half of error bars are drawn for readability). 


\subsection{Effects of seawater warming conditions}

Under reference temperature conditions, simulated biomasses differ along the latitudinal gradient (Fig. 6.a). Lower biomasses are simulated in southern areas and range from 2425 g.m

${ }^{2}$ to more than 5150 g. $\mathrm{m}^{-2}$ close to patch 110 . In the projection scenario, the geographical pattern of simulated biomass remains identical to that of the reference scenario, with a decrease in absolute values south of patch 125: $\mathrm{min} / \max =1805 / 5070 \mathrm{~g} \cdot \mathrm{m}^{-2}$. Biomasses plotted in temperature-food space can be viewed as the realized population niche (Fig. 6.b). Large differences were simulated along the food gradient, with a positive and significant relationship (linear regression: $\mathrm{R}^{2}=0.73 ; \mathrm{p}<0.001$ ), accounting for over $110 \%$ of variation. Response across the thermal range appears lower, with variations related to warming reaching $-27 \%$.

(a)

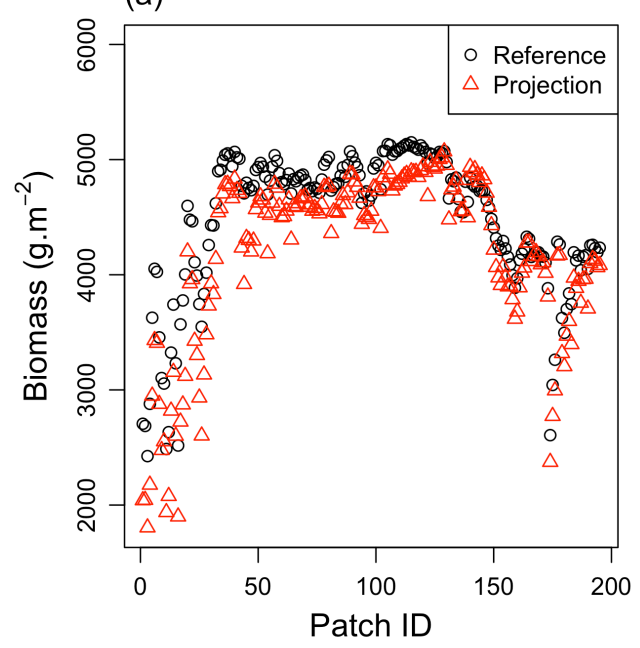

(b)

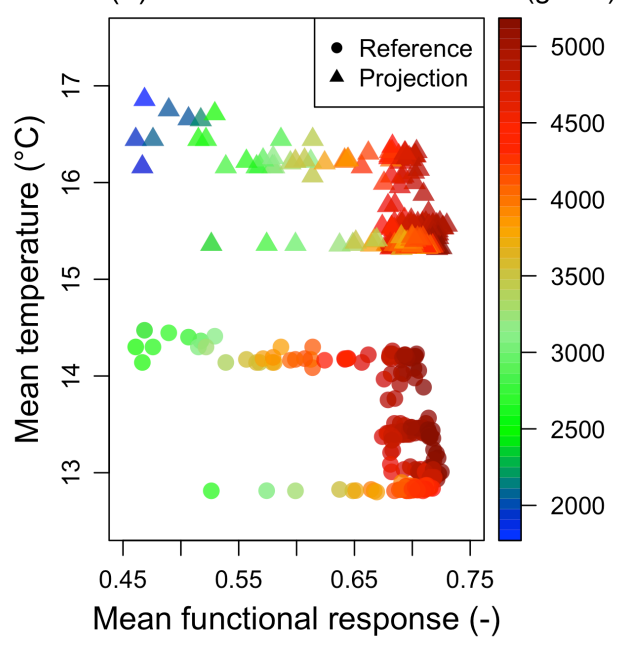

Fig. 6. Simulated biomass in reference and projection scenarios: (a) mean biomass simulated in every patch (patches are ordered from south to north of the study area) and (b) mean biomass simulated in every patch as a function of mean temperature and individual functional response (i.e., food effect) for the two temperature scenarios.

The mussel size distribution is modified by the seawater warming projection scenario (Fig. 7). Abundance of small individuals is significantly lower throughout the study area. This difference results in a mean individual length of $3.37 \mathrm{~cm}$ in the projection scenario compared with $3.29 \mathrm{~cm}$ in the reference scenario. This change in size structure is accompanied by a clear change in reproductive phenology (Fig. 8). A total halt in recruitment is simulated during the 
summer period throughout the study area. This phenomenon is associated with the upper

temperature threshold applied for reproduction. Conversely, the effect of the lower threshold seems to be noticeable in the northern part of the study area (patch $>125$ ), with an activation of recruitment during winter, which is not observed in the reference scenario. The overall average recruitment rate is thus significantly reduced from 9.3 to 8.2 recruits. $\mathrm{m}^{-2} \cdot \mathrm{month}^{-1}$ between the reference and projection scenarios, respectively. The patches in the south of the study area appear to be the most heavily penalized by decreased recruitment.

(a) Reference

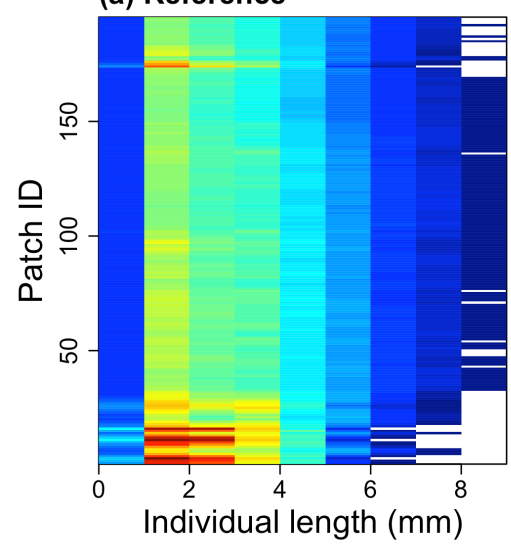

(b) Projection Abundance $\left(\times 10^{3}\right.$ ind $\left.\cdot \mathrm{m}^{-2}\right)$

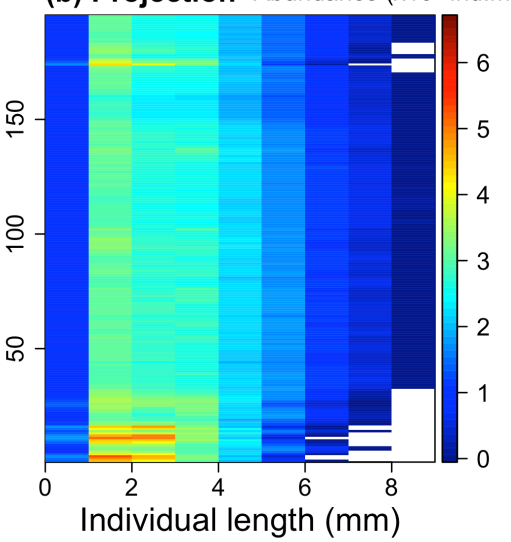

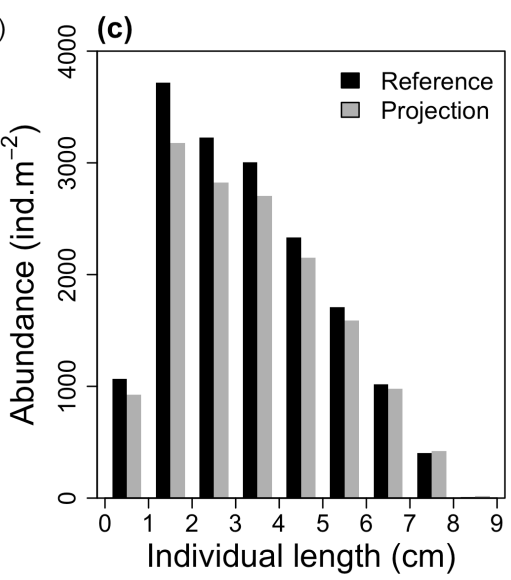

Fig. 7. Size frequency simulated over the studied area in the reference and projection scenarios: (a) monthly mean size frequency (expressed as abundance) in every patch in the reference scenario, (b) monthly mean size frequency (expressed as abundance) in every patch in the projection scenario and (c) monthly mean abundance, averaged over the studied area for the two scenarios.

(a) Reference

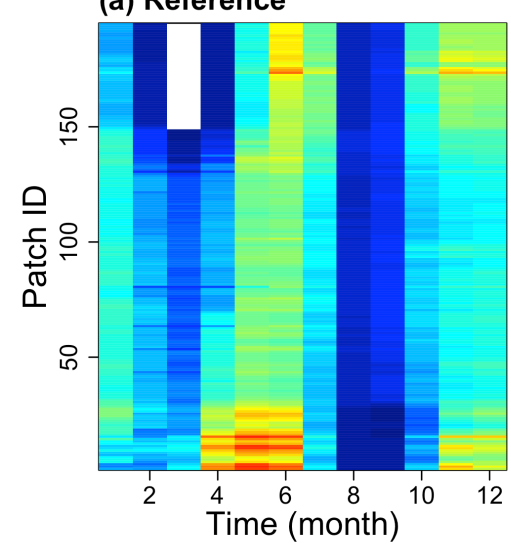

(b) Projection

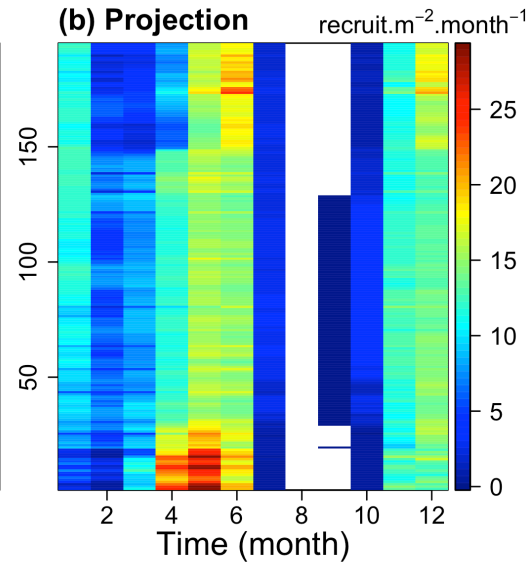

(c) Difference recruit. $\mathrm{m}^{-2}$ month $^{-1}$

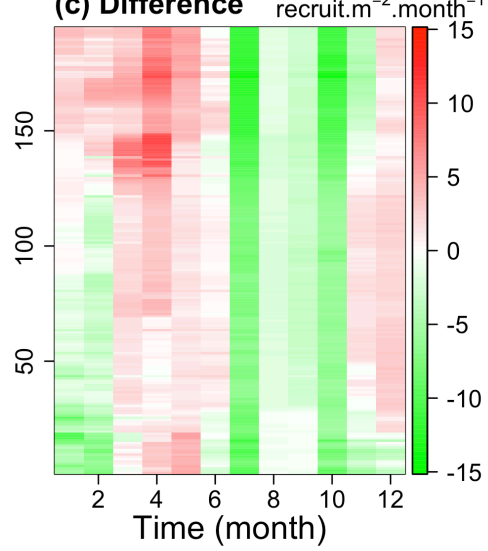

Fig. 8. Seasonal recruitment simulated over the studied area in the reference and projection scenarios: (a) monthly mean number of recruits in every patch in the reference scenario, (b) monthly mean number of recruits in every patch in the projection scenario and (c) difference in mean number of recruits between the two scenarios (projection - reference) in every patch. 


\subsection{Sensitivity analysis}

\subsubsection{Connectivity effect}

As previously described, simulated biomasses with the reference scenario (i.e. current temperature, monthly connectivity, PLD $=22$ days, average mortality and recruitment potential) show geographical heterogeneity, with lower biomasses in the south of the study area (Fig. 9). Biomasses stabilize in the centre of the study area (patch ID $>40$ ), before decreasing again in the north of the area (patch ID $>150$ ). When connectivity between patches is removed and only self-recruitment is considered, this general pattern of biomass variation is maintained, but biomasses are significantly lower. Average biomass decreases from $4480 \pm 620$ to $1401 \pm$ 510 g. $\mathrm{m}^{-2}$, corresponding to a mean decline of $69 \%$. Habitats in the south of the area can show biomasses very close to $0 \mathrm{~g} \cdot \mathrm{m}^{-2}\left(\min =5 \mathrm{~g} \cdot \mathrm{m}^{-2}\right)$.

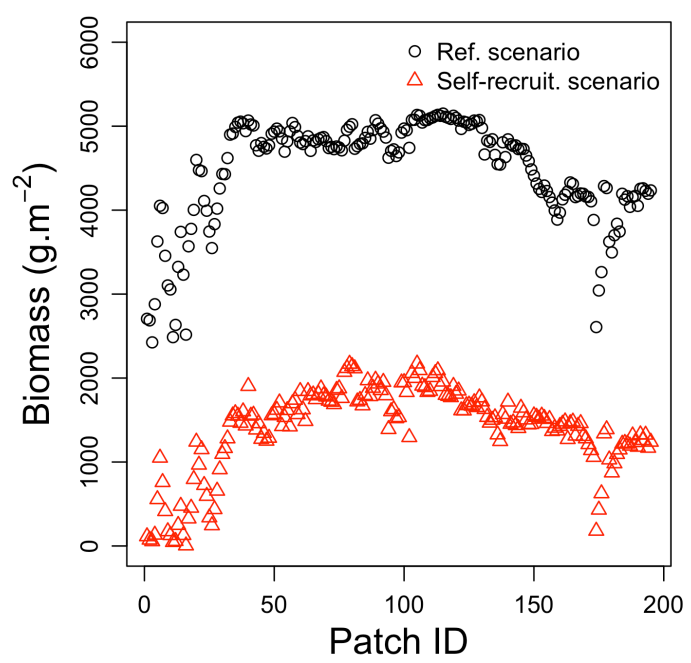

Fig. 9. Effect of population connectivity on simulated mussel biomass: biomass simulated in every habitat for the reference temperature scenario and with connectivity (ref.) or self-recruitment only. Data are averaged over the simulated period (15 years).

Beyond the direct effect on biomass, the simulations highlight that connectivity also mitigates the effect of the seawater warming scenario. If connectivity is removed and there is only self-recruitment, the decrease in biomass in the projection scenario is enhanced. On average, there is $22 \%$ lower biomass compared with the baseline simulation with monthly 
connectivity (Fig. 10.b-c). The other connectivity scenarios show that there is a limited effect of PLD and seasonal variation on biomass patterns. The three scenarios associated with PLD equal to 19 days and year-averaged connectivity tend to slightly limit the effect of warming by limiting biomass decline. Simulations show that the response has a spatial structure, with higher sensitivity in the south (patches 20 to 60) (Fig. 10.b). A possible edge effect appears at the extreme southern end of the study area, with results converging between the scenarios with and without connectivity.

(a)

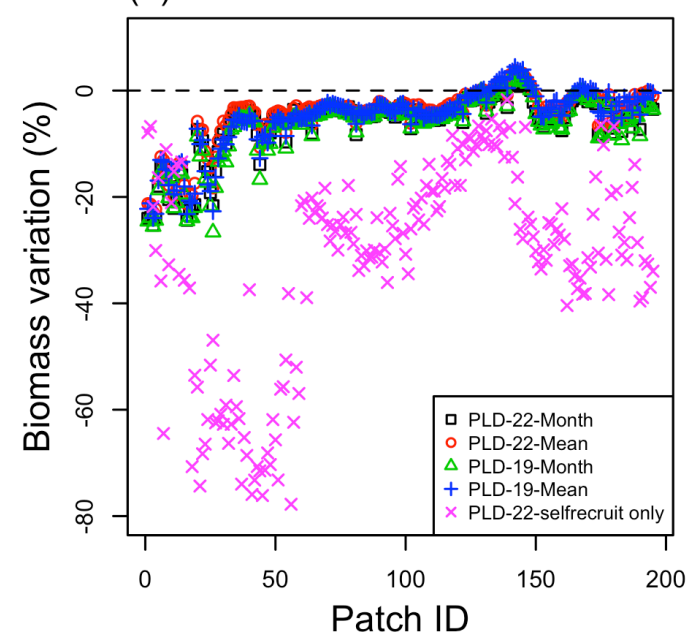

(b)

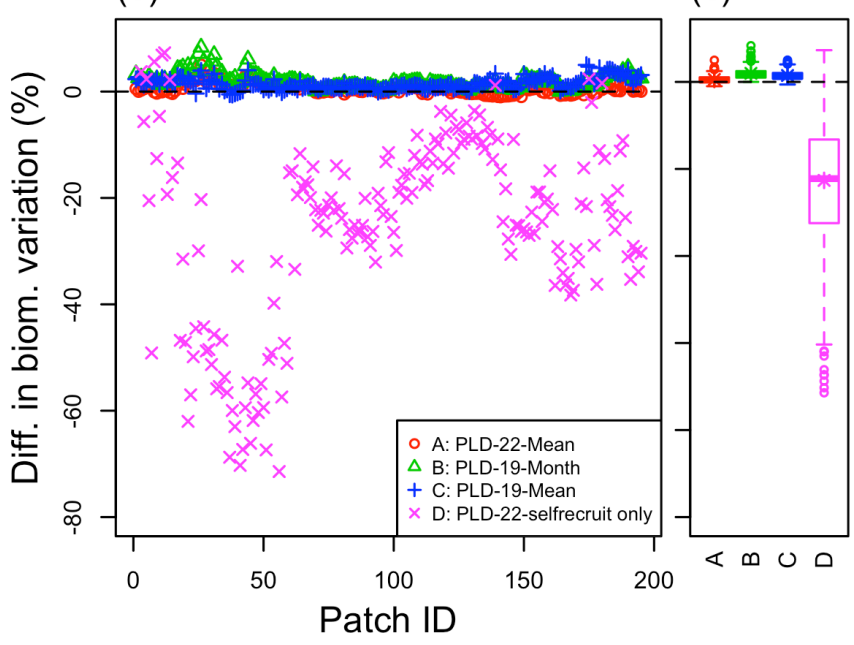

Fig. 10. Effect of habitat connectivity on mussel response to seawater warming scenario (RCP8.5): (a) difference in simulated biomass between the reference $(\mathrm{R})$ and projection $(\mathrm{P})$ temperature scenarios $(100 \times(P-R) / R, \%)$ in each patch and for each connectivity scenario, (b) difference in biomass variation between the realistic connectivity scenario ('PLD-22-Month') and the others, and (c) boxplot of the differences results, summarizing panel (b) for each connectivity scenario.

\subsubsection{Mortality and recruitment effects}

Whatever the scenario regarding mortality or recruitment potential, the response to the projection scenario shows the same pattern, with a decrease in simulated biomass in most of the habitats studied (Fig. 11.a, d, g). In a similar way to the reference model (monthly connectivity; PLD = 22 days; mean mortality and recruitment potential), the decrease in biomass is greater in the south of the study area. The effect of the mortality and recruitment potential scenarios on response to warming is relatively limited and differences with the 
reference model do not exceed $6 \%$ on average. However, this modulation is spatially heterogeneous. Southern habitats are systematically more sensitive and show larger differences from the reference model. The modulation is also non-symmetrical depending on whether the factor under consideration is increased or decreased. Increases in larval or post-larval mortality and decreases in recruitment potential have a greater effect on response to warming than decreases in these parameters. 
(a)

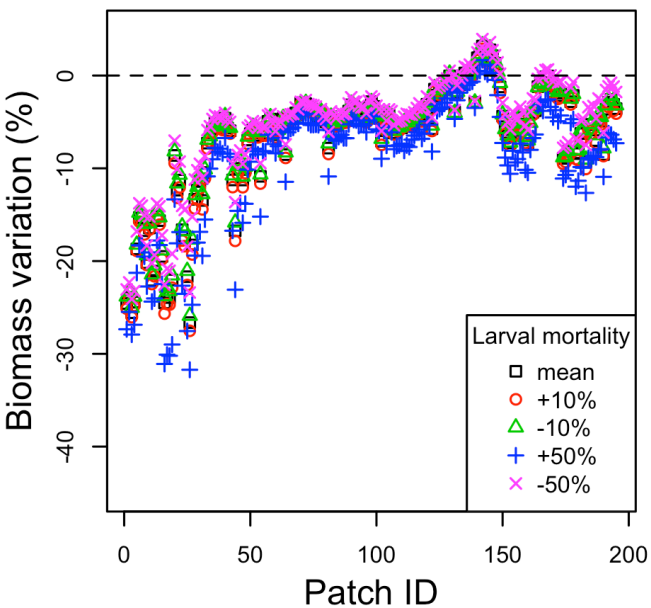

(d)

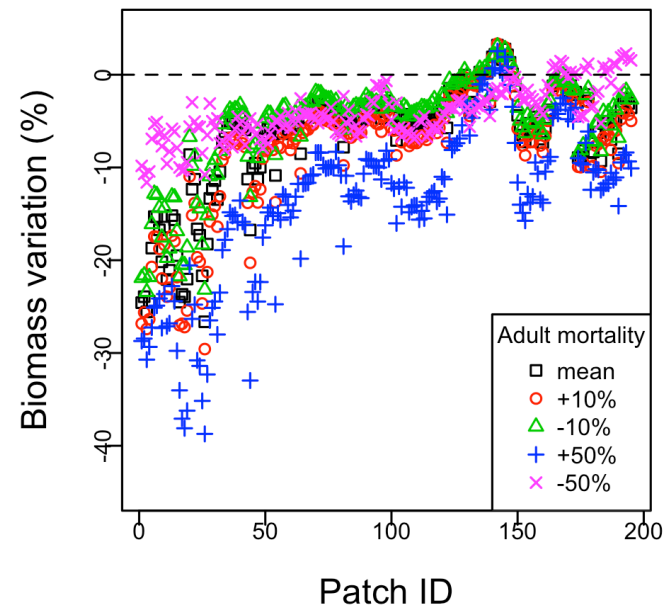

(g)

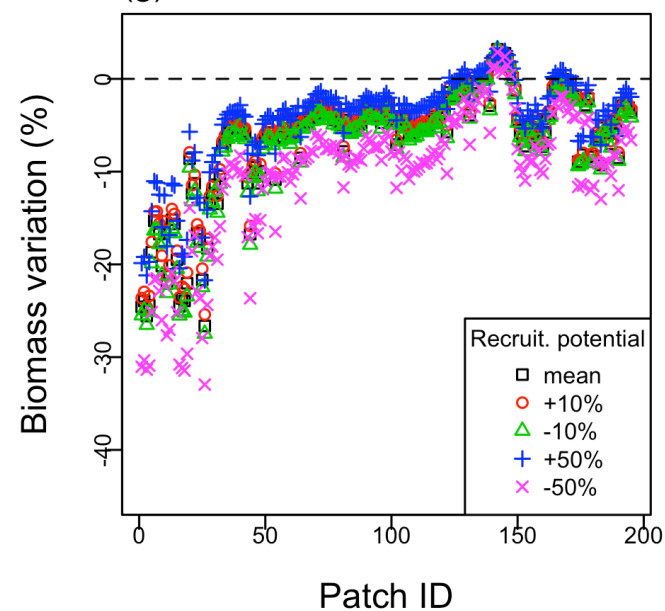

(b)

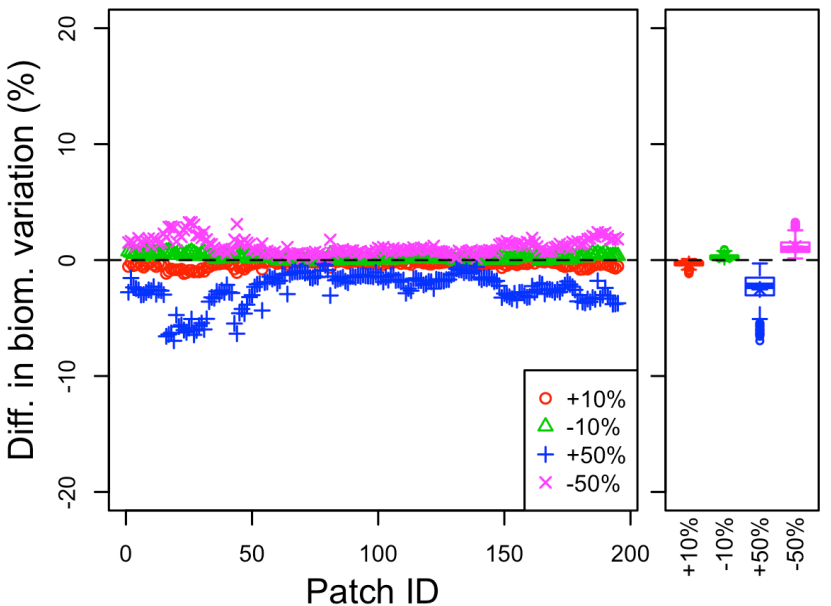

(e)

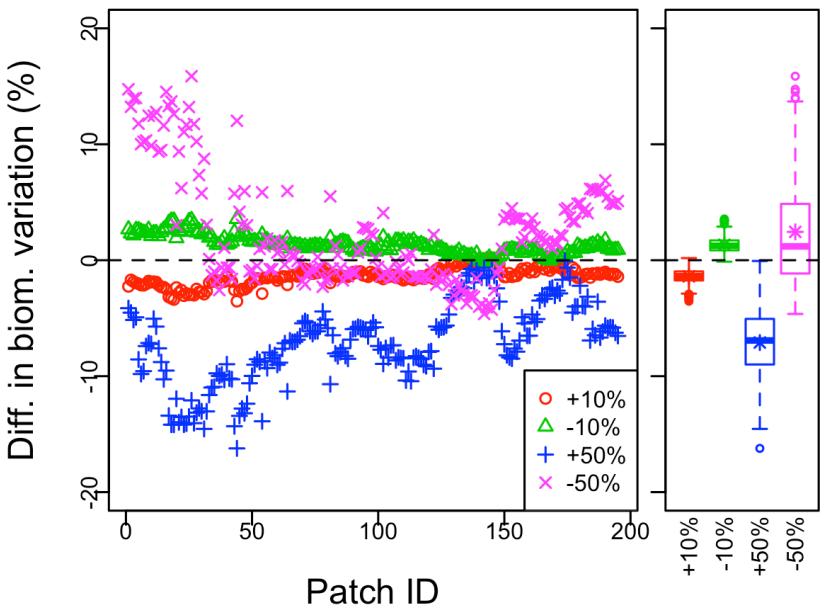

(h)

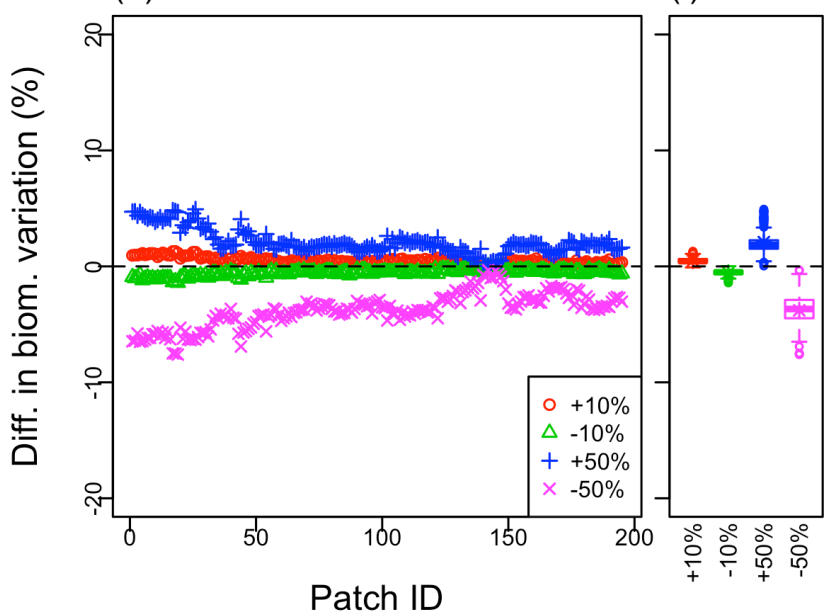

Fig. 11. Response to seawater warming scenario as a function of (a-c) larval mortality, (d-f) adult mortality and (g-i) recruitment potential. For each process tested, the three panels correspond to: (a, $\mathrm{d}, \mathrm{g})$ change $(\%)$ in simulated biomass between the reference $(\mathrm{R})$ and projection $(\mathrm{P})$ temperature scenarios $(100 \times(P-R) / R)$, in each patch; $(b, e, h)$ difference in biomass variation between the realistic scenario (here 'Mean') and the others; and (c, $f, i)$ boxplots of the differences results, summarizing the second panel for each scenario. 


\section{DISCUSSION}

\subsection{Results highlights}

Our results confirm the poleward latitudinal shift of a species distribution range resulting from global warming (Jones and Cheung, 2015; Jones et al., 2010). With the RCP8.5 scenario, our simulation showed a decrease in biomass ranging from $-27 \%$ in the south to $0 \%$ in the north of the study area, under the most realistic modelling conditions. We found that this decrease is related to a change in recruitment success and shift in reproduction phenology. This confirms previous results on the importance of reproductive phenology in the response of bivalve species to seawater warming (Thomas et al., 2016; Thomas and Bacher, 2018). The consequences of such an evolution are numerous for fishery and aquaculture activities (e.g. reduction in individual growth, standing stock biomass and recruitment success), but also for the balance of ecosystems (e.g. bentho-pelagic coupling, biodiversity associated with reef building, food web equilibrium). Our modelling approach is generic and is therefore applicable to many species with a bentho-pelagic life cycle. This would make it possible to evaluate consequences at the ecosystem scale, particularly by assessing the effects on material flows (biomasses, filtration rates, biodeposition, etc.) and food webs (impact on biodiversity at the local scale).

Previous studies did not account for the process of connectivity between populations or density regulation processes at the local scale of mussel patches (i.e. competition for space), which allow a realistic representation of biomass dynamics. In the present work, we modelled these processes of regulation and spatialization, allowing a relevant representation of population densities and size structures, comparable to data available in the literature. Our results highlight four major findings: (1) the temperatures projected by the RCP8.5 climate scenario to 2100 imply a decrease in average biomass and a shift in reproductive phenology, (2) the modulation response to temperature change is not spatially homogeneous, showing the 
importance of the processes implemented at the local scale, (3) the connectivity process clearly limits the consequences of seawater warming compared to other regulation processes, and (4) the larval supply does not seem to be a limiting element and only slightly modulates the response to temperature change. We will next examine the assumptions and implications of our results.

\subsection{Importance of local-scale processes: habitat definition}

The ecological niche concept locates species in the optimal zone of the environmental space that regulates their biomass. By considering temperature and food (here modulated by the density of inorganic particles), we have shown that the heterogeneity of trophic conditions is a key element that explains a large part of the simulated biomass variability. Nearly $110 \%$ biomass variation was simulated between the most contrasting habitats in our baseline scenario along the trophic gradient, compared with a maximum of $-27 \%$ along the thermal gradient. However, our approach does not consider the complexity of the thermal conditions that may exist at a small scale. This has already been well demonstrated in rocky intertidal habitats, notably through the concept of a mosaic of thermal environments (Helmuth et al., 2002). Since our study area was not located at the extreme limit of the species range, we considered that the temperatures used should reflect average conditions and that the physiological extremes were not reached. However, this assumption highlights the importance of considering the processes prevailing at a small scale that modulate both physiological performances and biotic interactions.

Here, we defined the potential habitat as rocky intertidal areas, which were derived from the products of the European EMODNET Seabed Habitats project (Thomas and Bacher, 2018). In our model, we hypothesized that colonization of this habitat by mussels would take place depending on two conditions: i) local food concentration must support mussel individual 
growth and reproduction, and ii) connectivity between habitats and self-recruitment within a given habitat would maintain the recruitment of individuals high enough to compensate for the mortality of new recruits, juveniles and adult mussels. All our modelled patches match these conditions. We also accounted for the competition for space using a simple rule linking space availability to the size and density of mussels already present in a patch. Simulations showed that all the space was eventually occupied, and we found that differences between patches and temporal variability of mussel density merely resulted from growth differences due to local food concentration. Therefore, the predicted mussel density and biomass can be seen as proxies of the actual values, and the results interpreted in terms of the relative differences between scenarios.

More realistic predictions of mussel biomass would require i) a better estimation of the area of potential habitat within each patch and ii) to determine the local factors that limit the occupation of potential habitat (i.e. realized habitat). The spatial resolution of the EMODNET layers we used to identify the different type of habitats may be not sufficient to represent coastal intertidal habitats, though we do not know of any work addressing this issue. Spatial resolution is an issue addressed in Species Distribution Modelling, and some authors have shown that it has an effect on model performance (Lowen et al., 2016). Gomes et al. (2018) recently presented the advantages of aerial photography for investigating large-scale patterns of mussel distribution in intertidal mud and sand flats. They pointed out the lack of studies quantifying mussel distribution on rocky shores and demonstrated how the use of aerial photography with a drone helps us to understand mussel distribution in such habitats. Through the combination of image analysis and habitat suitability model at a high spatial resolution, they mapped the density, mean size and reproductive effort of Mytilus galloprovincialis along the Portuguese rocky intertidal coastline. Density ranged from 0 to 6500 ind. $\mathrm{m}^{-2}$, which compares well with the values we found with our model. Mussel coverage (ratio mussels/rocky substrate) varied 
between $0.4 \%$ up to $60 \%$ depending on location. They also found a significant relationship between wave exposure and the density and distribution of mussel populations and argued that wave action forces intertidal organisms to adapt and withstand the dynamics of water motion. Physical drivers would explain, at least partly, the distribution of mussel populations, and Gomes et al. (2018) concluded that location-specific predictions can be used in metapopulation models. Considering the effect of physical drivers in addition to the bioenergetics of organisms and the connectivity between patches would, therefore improve the quantitative predictions of our models. The development of habitat observation tools (e.g. highresolution photogrammetry) combined with tools for modelling (e.g. microclimate conditions, Kearney et al., 2020) offer promising prospects in this context (Choi et al., 2019).

\subsection{The two sides to larval supply: larval production and connectivity}

'Supply-side ecology' recognizes that variable larval input is a key factor determining the size of local adult populations (Hughes et al., 2000). However, as Hughes et al. (2000) point out, the spatial scale at which adult stocks and recruitment are coupled is unknown for most marine organisms. By decoupling these two processes, our results highlight the lower effect of larval supply relative to the connectivity potential. A variation of $\pm 50 \%$ in larval mortality, which could be associated with a significant decrease in reproductive efficiency, modulates the response to the projection scenario by less than $\pm 5 \%$, compared with the $-22 \%$ simulated by our 'self-recruitment' scenario. The comparison between the 'self-recruitment' and reference (with connectivity) scenarios also showed that the response of mussel biomass to temperature change was more sensitive to connectivity than to any other factor we tested (Fig. S6). Mussel biomass would also be reduced by $70 \%$ if self-recruitment was the only process of population renewal.

Our simulations also give an idea of the dispersal capacity and dispersion range of mussel populations. Additional simulations (Fig. S7) indicate that the southernmost mussel population 
in this study would need 13 years to reach the most northern set of patches and that mussels never propagate from north to south, reflecting the asymmetry in the connectivity matrix and breakpoints associated with environmental conditions limiting sufficient reproductive capacity. Ayata et al. (2010) simulated connectivity in the same region and also showed that the Ushant Sea, which lies between the western English Channel and northeast Bay of Biscay, likely acts as a partly permeable one-way barrier. However, there is very little quantitative information on spatial dispersion of mussel propagules, and most observations, calculations or hypotheses give values between a few kilometres up to $100 \mathrm{~km}$. In their modelling of mussel dispersion along the French Atlantic coast, Wethey et al. (2011) assumed that the spatial scale of dispersal was $25 \mathrm{~km}$ and argued that this value is typical of the dispersal ranges of intertidal species with planktonic larvae. In South Africa, McQuaid and Phillips (2000) found that the dispersal radius would maintain $90 \%$ of the intertidal mussel Mytilus galloprovincialis population within an area of $5 \mathrm{~km}$, while the maximum effective dispersal of mussel larvae in this area would be less than $100 \mathrm{~km}$. Gilg et al. (2007) found exchanges of $M$. edulis and M. galloprovincialis larvae possible over distances $>100 \mathrm{~km}$ though barriers to dispersal could occur at some locations. For another mussel species, model projections made by Gilg et al. (2014) suggested that dispersal distance could exceed $100 \mathrm{~km}$. Carsons et al. (2010) identified larval source populations of mussels species and found dispersal distances around $35 \mathrm{~km}$. These examples show that, for intertidal species like mussels, hydrodynamics control the spread of populations and should be investigated in more detail. Following the work of Nicolle et al. (2017) and Ménesguen et al. (2018) on other benthic species, it would be interesting to extend our calculation to a larger set of patches extending to the north of the English Channel and to assess the kernel and barriers to dispersion at a larger spatial scale. 


\subsection{Larval behaviour and phase duration}

We assumed that the pelagic phase duration was spatially homogeneous and constant in a given scenario, and that the larvae were transported passively, with no swimming behaviour. Testing the effect of pelagic larval phase duration showed that changes of biomass in response to temperature change were not very sensitive to this parameter.

We have not found any similar studies addressing the effect of larval swimming on mussel larvae dispersion and metapopulation connectivity. Other authors made different assumptions depending on the species of interest, modelling scope or available information, and conclusions on the need for incorporating behaviour do not converge. McQuaid and Philipps (2000) estimated that passive transport was sufficient to explain the abundances of larvae in their region of interest. Kim et al. (2013) found that physical forcing showed a greater influence on the loss of $C$. virginica larvae than did behaviour. but North et al. (2008) found that behaviour had significant consequences for dispersal distances, transport success, and the degree of connectivity between subpopulations. Hubbard and Reidenbach (2015) follow the same line, concluding that changes in swimming behaviour due to turbulence influence the probability of settling of $C$. virginica on suitable substrate. This apparent contradiction regarding the need, or lack thereof, to account for larval behaviour, can be explained by sources of variability considered and the hypotheses tested. In our model, we emphasized multiple spawnings within mussel populations, due to local differences in individual growth and reproduction. Emissions of larvae at different times of the year would generate new cohorts of individuals with different life histories and spawning events. This cascade effect yields a large variability of life history traits within each population and contributes to the variability of larval transport. 


\subsection{Conclusion}

The effect of a climate warming scenario, currently considered to be the most severe of the projections, appears to be strongly modulated by processes occurring at multiple scales. At the local scale, food availability remains a major factor structuring biomass, and neither ontogenic mortality nor recruitment potential seem to strongly modulate the response. At the study area scale, the connectivity between populations mitigates the consequences of warming by limiting the loss of biomass locally. These results are made in a restricted biogeographic transition zone. The same approach would merit being established over the entire range of the species to assess whether this observation remains homogeneous. The generic nature of the approach developed will also make it possible to compare the response of other species.

Our model is constructed of solid elements, based on well-established theories and processes. It produces results that have demonstrated their realism and robustness to sensitivity analysis. We need, however, to know more about the realized habitat in order to have a more quantitative approach of realized niche. Connectivity appears to be a determining factor, and patterns of population connectivity could be strongly modified by local processes limiting the occupation of potential habitats. The next step in the implementation of such a population dynamics modelling approach would be to have a more realistic representation of the realized habitat, in order to get as close as possible to the true connectivity (sensu Watson et al., 2010).

Identifying and prioritizing the processes likely to modulate the multi-scale response of species to climate change is a key element in predicting the dynamics of marine ecosystems in a context of increasing pressures such as seawater warming, hypoxia events, acidification, overexploitation, pollution, etc. As biological responses, socio-economic and administrative aspects are not spatially homogeneous (Barillé et al., 2020), the integration of spatial processes into a spatially explicit modelling (SEM) strategy appears to be the decisive difference from spatially implicit models (SIMs), which are more oriented towards theoretical issues 
(DeAngelis and Yurek, 2017). The use of such models, with a generic approach, would

make it possible to provide scientific support to guide and optimize research efforts, e.g. define key field observations, experimentation and operational modelling strategies, and support the implementation of management and conservation measures.

\section{ACKNOWLEDGEMENTS}

This research was supported by a grant from Région Bretagne (SAD POPDEB n 9277 ) and Ifremer. Authors thank M. Vasquez (Ifremer, DYNECO) for assembling the EUSeaMap seabed habitat mapping information and C. Cassou (CNRS, Cerfacs) for putting together the climate model datasets. We thank Helen McCombie for English editing and her valuable comments and anonymous reviewers for their comments which improved our manuscript.

\section{REFERENCES}

Alunno-Bruscia, M., Bourget, E., Fréchette, M., 2001. Shell allometry and length-mass-density relationship for Mytilus edulis in an experimental food-regulated situation. Marine Ecology Progress Series 219, 177-188.

Alunno-Bruscia, M., Bourlès, Y., Maurer, D., Robert, S., Mazurié, J., Gangnery, A., Goulletquer, P., Pouvreau, S., 2011. A single bio-energetics growth and reproduction model for the oyster Crassostrea gigas in six Atlantic ecosystems. Journal of Sea Research 66, 340-348.

Ayata, S.-D., Lazure, P., Thiébaut, E., 2010. How does the connectivity between populations mediate range limits of marine invertebrates? A case study of larval dispersal between the Bay of Biscay and the English Channel (North-East Atlantic). Progress In Oceanography $87,18-36$.

Barillé, L., Bris, A.L., Goulletquer, P., Thomas, Y., Glize, P., Kane, F., Falconer, L., Guillotreau, P., Trouillet, B., Palmer, S., Gernez, P., 2020. Biological, socio-economic, and administrative opportunities and challenges to moving aquaculture offshore for small French oyster-farming companies. Aquaculture 735045. https://doi.org/10.1016/j.aquaculture.2020.735045

Carson, H.S., López-Duarte, P.C., Rasmussen, L., Wang, D., Levin, L.A., 2010. Reproductive Timing Alters Population Connectivity in Marine Metapopulations. Current Biology 20, 1926-1931. https://doi.org/10.1016/j.cub.2010.09.057

Choi, F., Gouhier, T., Lima, F., Rilov, G., Seabra, R., Helmuth, B., 2019. Mapping physiology: biophysical mechanisms define scales of climate change impacts. Conserv Physiol 7. https://doi.org/10.1093/conphys/coz028 
Coscia, I., Robins, P.E., Porter, J.S., Malham, S.K., Ironside, J.E., 2013. Modelled larval dispersal and measured gene flow: seascape genetics of the common cockle Cerastoderma edule in the southern Irish Sea. Conserv Genet 14, 451-466. https://doi.org/10.1007/s10592-012-0404-4

Davies, K.T.A., Gentleman, W.C., DiBacco, C., Johnson, C.L., 2014. Semi-annual spawning in marine scallops strengthens larval recruitment and connectivity on Georges Bank: a model study. Marine Ecology Progress Series 516, 209-227. https://doi.org/10.3354/meps10975

DeAngelis, D.L., Yurek, S., 2017. Spatially Explicit Modeling in Ecology: A Review. Ecosystems 20, 284-300. https://doi.org/10.1007/s10021-016-0066-Z

Dormann, C.F., Schymanski, S.J., Cabral, J., Chuine, I., Graham, C., Hartig, F., Kearney, M., Morin, X., Römermann, C., Schröder, B., Singer, A., 2012. Correlation and process in species distribution models: bridging a dichotomy. Journal of Biogeography 39, 2119 2131. https://doi.org/10.1111/j.1365-2699.2011.02659.x

Dye, S., Hughes, S.L., Tinker, J., Berry, D.I., Holliday, N.P., Kent, E.C., Kennington, K., Inall, M., Smythe, T., Nolan, G., Lyons, K., Andres, O., Beszczynska-Möller, A., 2013. Impacts of climate change on temperature (air and sea), in: Buckley, P.J., Baxter, J.M., Wallace, C.J. (Eds.), Marine Climate Change Impacts Partnership Science Review 2013. MCCIP Secretariat.

Fearman, J., Moltschaniwskyj, N.A., 2010. Warmer temperatures reduce rates of gametogenesis in temperate mussels, Mytilus galloprovincialis. Aquaculture 305, 20 25. https://doi.org/10.1016/j.aquaculture.2010.04.003

Fly, E.K., Hilbish, T.J., Wethey, D.S., Rognstad, R.L., 2015. Physiology and Biogeography: The Response of European Mussels (Mytilus spp.) to Climate Change. American Malacological Bulletin 33, 136-149. https://doi.org/10.4003/006.033.0111

Gilg, M.R., Howard, R., Turner, R., Middlebrook, M., Abdulnour, M., Lukaj, E., Sheng, Y.P., Liu, T., Tutak, B., 2014. Estimating the dispersal capacity of the introduced green mussel, Perna viridis (Linnaeus, 1758), from field collections and oceanographic modeling. Journal of Experimental Marine Biology and Ecology 461, 233-242. https://doi.org/10.1016/j.jembe.2014.08.004

Gilg, M.R., Kirby, S.E., Sullivan, R., Knapp, L.W., Hilbish, T.J., 2007. Dispersal vs. retention: correspondence of species-specific reproductive cycles and settlement periods in a blue mussel hybrid zone. Marine Ecology Progress Series 351, 151-161. https://doi.org/10.3354/meps07145

Gohin, F., Druon, J.N., Lampert, L., 2002. A five channel chlorophyll concentration algorithm applied to SeaWiFS data processed by SeaDAS in coastal waters. Int. J. Remote Sens. 23, 1639-1661. https://doi.org/10.1080/01431160110071879

Gomes, I., Peteiro, L., Bueno-Pardo, J., Albuquerque, R., Pérez-Jorge, S., Oliveira, E.R., Alves, F.L., Queiroga, H., 2018. What's a picture really worth? On the use of drone aerial imagery to estimate intertidal rocky shore mussel demographic parameters. Estuarine, Coastal and Shelf Science 213, 185-198. https://doi.org/10.1016/j.ecss.2018.08.020

Grimm, V., Berger, U., Bastiansen, F., Eliassen, S., Ginot, V., Giske, J., Goss-Custard, J., Grand, T., Heinz, S.K., Huse, G., Huth, A., Jepsen, J.U., Jørgensen, C., Mooij, W.M., Müller, B., Pe'er, G., Piou, C., Railsback, S.F., Robbins, A.M., Robbins, M.M., Rossmanith, E., Rüger, N., Strand, E., Souissi, S., Stillman, R.A., Vabø, R., Visser, U., 
DeAngelis, D.L., 2006. A standard protocol for describing individual-based and agent-based models. Ecological Modelling 198, 115-126. https://doi.org/10.1016/j.ecolmodel.2006.04.023

Grimm, V., Berger, U., DeAngelis, D.L., Polhill, J.G., Giske, J., Railsback, S.F., 2010. The ODD protocol: A review and first update. Ecological Modelling 221, 2760-2768. https://doi.org/10.1016/j.ecolmodel.2010.08.019

Guizien, K., Belharet, M., Marsaleix, P., Guarini, J.M., 2012. Using larval dispersal simulations for marine protected area design: Application to the Gulf of Lions (northwest Mediterranean). Limnology and Oceanography 57, 1099-1112. https://doi.org/10.4319/1o.2012.57.4.1099

Guizien, K., Belharet, M., Moritz, C., Guarini, J.M., 2014. Vulnerability of marine benthic metapopulations: implications of spatially structured connectivity for conservation practice in the Gulf of Lions (NW Mediterranean Sea). Diversity Distrib. 20, 13921402. https://doi.org/10.1111/ddi.12254

Haase, A.T., Eggleston, D.B., Luettich, R.A., Weaver, R.J., Puckett, B.J., 2012. Estuarine circulation and predicted oyster larval dispersal among a network of reserves. Estuarine, Coastal and Shelf Science 101, 33-43. https://doi.org/10.1016/j.ecss.2012.02.011

Hawkins, S.J., Moore, P.J., Burrows, M.T., Poloczanska, E., Mieszkowska, N., Herbert, R.J.H., Jenkins, S.R., Thompson, R.C., Genner, M.J., Southward, A.J., 2008. Complex interactions in a rapidly changing world: responses of rocky shore communities to recent climate change. Climate Research 37, 123-133. https://doi.org/10.3354/cr00768

Hawkins, S.J., Sugden HE, Mieszkowska N, Moore PJ, Poloczanska E, Leaper R, Herbert RJH, Genner MJ, Moschella PS, Thompson RC, Jenkins SR, Southward AJ, Burrows MT, 2009. Consequences of climate-driven biodiversity changes for ecosystem functioning of North European rocky shores. Mar Ecol Prog Ser 396, 245-259.

Helmuth, B., Harley, C.D.G., Halpin, P.M., O’Donnell, M., Hofmann, G.E., Blanchette, C.A., 2002. Climate Change and Latitudinal Patterns of Intertidal Thermal Stress. Science 298, 1015-1017.

Hilbish, T.J., Lima, F.P., Brannock, P.M., Fly, E.K., Rognstad, R.L., Wethey, D.S., 2012. Change and stasis in marine hybrid zones in response to climate warming. Journal of Biogeography 39, 676-687. https://doi.org/10.1111/j.1365-2699.2011.02633.x

Hubbard, A.B., Reidenbach, M.A., 2015. Effects of larval swimming behavior on the dispersal and settlement of the eastern oyster Crassostrea virginica. Marine Ecology Progress Series 535, 161-176. https://doi.org/10.3354/meps1 1373

Hughes, T.P., Baird, A.H., Dinsdale, E.A., Moltschaniwskyj, N.A., Pratchett, M.S., Tanner, J.E., Willis, B.L., 2000. Supply-side ecology works both ways: the link between benthic adults, fecundity, and larval recruits. Ecology 81, 2241-2249.

Jolly, M.T., Jollivet, D., Gentil, F., Thiebaut, E., Viard, F., 2004. Sharp genetic break between Atlantic and English Channel populations of the polychaete Pectinaria koreni, along the North coast of France. Heredity 94, 23-32.

Jones, M.C., Cheung, W.W.L., 2015. Multi-model ensemble projections of climate change effects on global marine biodiversity. ICES Journal of Marine Science 72, 741-752. https://doi.org/10.1093/icesjms/fsu172 
Jones, S.J., Lima, F.P., Wethey, D.S., 2010. Rising environmental temperatures and biogeography: poleward range contraction of the blue mussel, Mytilus edulis L., in the western Atlantic. Journal of Biogeography 37, 2243-2259. https://doi.org/10.1111/j.1365-2699.2010.02386.x

Kearney, M., 2006. Habitat, environment and niche: what are we modelling? Oikos 115, 186191. https://doi.org/10.1111/j.2006.0030-1299.14908.x

Kearney, M., Simpson, S.J., Raubenheimer, D., Helmuth, B., 2010. Modelling the ecological niche from functional traits. Philosophical Transactions of the Royal Society B: Biological Sciences 365, 3469-3483.

Kearney, M.R., Gillingham, P.K., Bramer, I., Duffy, J.P., Maclean, I.M.D., 2020. A method for computing hourly, historical, terrain-corrected microclimate anywhere on earth. Methods in Ecology and Evolution 11, 38-43. https://doi.org/10.1111/2041210X.13330

Kim, C.-K., Park, K., Powers, S.P., 2013. Establishing Restoration Strategy of Eastern Oyster via a Coupled Biophysical Transport Model. Restoration Ecology 21, 353-362. https://doi.org/10.1111/j.1526-100X.2012.00897.x

Kooijman, S.A.L.M., 2010. Dynamic Energy Budget Theory for Metabolic Organisation. Cambridge University Press, Cambridge.

Kooijman, S.A.L.M., 2006. Pseudo-faeces production in bivalves. Journal of Sea Research 56, 103-106.

Lal, M.M., Southgate, P.C., Jerry, D.R., Bosserelle, C., Zenger, K.R., 2016. A Parallel Population Genomic and Hydrodynamic Approach to Fishery Management of HighlyDispersive Marine Invertebrates: The Case of the Fijian Black-Lip Pearl Oyster Pinctada margaritifera. PLoS ONE 11, e0161390. https://doi.org/10.1371/journal.pone.0161390

Laugen, A.T., Hollander, J., Obst, M., Strand, Å., 2015. 10. The Pacific Oyster (Crassostrea gigas) Invasion in Scandinavian Coastal Waters: Impact on Local Ecosystem Services, in: Canning-Clode, J. (Ed.), Biological Invasions in Changing Ecosystems. De Gruyter Open, Warsaw, Poland. https://doi.org/10.1515/9783110438666-015

Lazure, P., Dumas, F., 2008. An external-internal mode coupling for a 3D hydrodynamical model for applications at regional scale (MARS). Advances in Water Resources 31, 233-250.

Le Goff, C., Lavaud, R., Cugier, P., Jean, F., Flye-Sainte-Marie, J., Foucher, E., Desroy, N., Fifas, S., Foveau, A., 2017. A coupled biophysical model for the distribution of the great scallop Pecten maximus in the English Channel. Journal of Marine Systems 167, 5567. https://doi.org/10.1016/j.jmarsys.2016.10.013

Lett, C., Ayata, S.-D., Huret, M., Irisson, J.-O., 2010. Biophysical modelling to investigate the effects of climate change on marine population dispersal and connectivity. Progress in Oceanography 87, 106-113. https://doi.org/10.1016/j.pocean.2010.09.005

L'Hévéder, B., Speich, S., Ragueneau, O., Gohin, F., Bryère, P., 2017. Observed and projected sea surface temperature seasonal changes in the Western English Channel from satellite data and CMIP5 multi-model ensemble. International Journal of Climatology 37, 28312849. https://doi.org/10.1002/joc.4882 
Lowen, J.B., McKindsey, C.W., Therriault, T.W., DiBacco, C., 2016. Effects of spatial resolution on predicting the distribution of aquatic invasive species in nearshore marine environments. Marine Ecology Progress Series 556, 17-30. https://doi.org/10.3354/meps11765

Lubet, P., 1959. Recherches sur le cycle sexuel et l'émission des gamètes chez les Mytilidés et les Pectinidés (Mollusques bivalves). Revue des Travaux de l'Institut des Pêches Maritimes 23, 397-547.

Malishev, M., Bull, C.M., Kearney, M.R., 2018. An individual-based model of ectotherm movement integrating metabolic and microclimatic constraints. Methods in Ecology and Evolution 9, 472-489. https://doi.org/10.1111/2041-210X.12909

Martin, B.T., Zimmer, E.I., Grimm, V., Jager, T., 2012. Dynamic Energy Budget theory meets individual-based modelling: a generic and accessible implementation. Methods in Ecology and Evolution 3, 445-449. https://doi.org/10.1111/j.2041-210X.2011.00168.x

Martin, M., Dash, P., Ignatov, A., Banzon, V., Beggs, H., Brasnett, B., Cayula, J.-F., Cummings, J., Donlon, C., Gentemann, C., Grumbine, R., Ishizaki, S., Maturi, E., Reynolds, R.W., Roberts-Jones, J., 2012. Group for High Resolution Sea Surface temperature (GHRSST) analysis fields inter-comparisons. Part 1: A GHRSST multiproduct ensemble (GMPE). Deep-Sea Res. Pt. II 77-80, 21-30. https://doi.org/10.1016/j.dsr2.2012.04.013

McQuaid, C.D., Phillips, T.E., 2000. Limited wind-driven dispersal of intertidal mussel larvae: in situ evidence from the plankton and the spread of the invasive species Mytilus galloprovincialis in South Africa. Marine Ecology Progress Series 201, 211-220. https://doi.org/10.3354/meps201211

Ménesguen, A., Hachet, A., Grégoris, T., 2018. Modelling benthic invasion by the colonial gastropod Crepidula fornicata and its competition with the bivalve Pecten maximus. 2. Coupling the $0 \mathrm{D}$ model of colony-forming species to a connectivity matrix for a realistic distributed simulation of benthic invasion. Ecological Modelling 375, 30-44. https://doi.org/10.1016/j.ecolmodel.2018.02.015

Montalto, V., Helmuth, B., Ruti, P.M., Dell'Aquila, A., Rinaldi, A., Sarà, G., 2016. A mechanistic approach reveals non linear effects of climate warming on mussels throughout the Mediterranean sea. Climatic Change 139, 293-306. https://doi.org/10.1007/s10584-016-1780-4

Nicolle, A., Dumas, F., Foveau, A., Foucher, E., Thiébaut, E., 2013. Modelling larval dispersal of the king scallop (Pecten maximus) in the English Channel: examples from the bay of Saint-Brieuc and the bay of Seine. Ocean Dynamics 63, 661-678. https://doi.org/10.1007/s10236-013-0617-1

Nicolle, A., Moitié, R., Ogor, J., Dumas, F., Foveau, A., Foucher, E., Thiébaut, E., 2017. Modelling larval dispersal of Pecten maximus in the English Channel: a tool for the spatial management of the stocks. ICES J Mar Sci 74, 1812-1825. https://doi.org/10.1093/icesjms/fsw207

North, E.W., King, D.M., Xu, J., Hood, R.R., Newell, R.I.E., Paynter, K., Kellogg, M.L., Liddel, M.K., Boesch, D.F., 2010. Linking optimization and ecological models in a decision support tool for oyster restoration and management. Ecological Applications 20, 851-866. https://doi.org/10.1890/08-1733.1 
North, E.W., Schlag, Z., Hood, R.R., Li, M., Zhong, L., Gross, T., Kennedy, V.S., 2008. Vertical swimming behavior influences the dispersal of simulated oyster larvae in a coupled particle-tracking and hydrodynamic model of Chesapeake Bay. Marine Ecology Progress Series 359, 99-115.

Opaluch, J.J., Anderson, J.L., Schnier, K., 2009. A Risk-Based Approach to Managing the Intentional Introduction of Non-Native Species 23.

Puckett, B.J., Eggleston, D.B., 2016. Metapopulation dynamics guide marine reserve design: importance of connectivity, demographics, and stock enhancement. Ecosphere 7, e01322. https://doi.org/10.1002/ecs2.1322

R Development Core Team, 2012. R: A language and environment for statistical computing. R Foundation for Statistical Computing, Vienna, Austria. http://www.R-project.org/.

Roughgarden, J., Iwasa, Y., Baxter, C., 1985. Demographic Theory for an Open Marine Population with Space-Limited Recruitment. Ecology 66, 54-67. https://doi.org/10.2307/1941306

Saraiva, S., Van Der Meer, J., Kooijman, S.A.L.M., Witbaard, R., Philippart, C.J.M., Hippler, D., Parker, R., 2012. Validation of a Dynamic Energy Budget (DEB) model for the blue mussel Mytilus edulis. Mar Ecol Prog Ser 463, 141-158.

Saulquin, B., Gohin, F., 2010. Mean seasonal cycle and evolution of the sea surface temperature from satellite and in situ data in the English Channel for the period 1986-2006. International Journal of Remote Sensing 31, 4069-4093. https://doi.org/10.1080/01431160903199155

Saulquin, B., Gohin, F., Garrello, R., 2011. Regional Objective Analysis for Merging HighResolution MERIS, MODIS/Aqua, and SeaWiFS Chlorophyll-a Data From 1998 to 2008 on the European Atlantic Shelf. IEEE Trans. Geosci. Remote Sens. 49, 143-154. https://doi.org/10.1109/TGRS.2010.2052813

Scheffer, M., Baveco, J.M., DeAngelis, D.L., Rose, K.A., van Nes, E.H., 1995. Superindividuals a simple solution for modelling large populations on an individual basis. Ecological Modelling 80, 161-170. https://doi.org/10.1016/0304-3800(94)00055-M

Shpigel, M., Barber, B.J., Mann, R., 1992. Effects of elevated temperature on growth, gametogenis, physiology, and biochemical composition in diploid and triploid Pacific oysters: Crassostrea gigas Thunberg. Journal of Experimental Marine Biology and Ecology 161, 15-25.

Southward, A.J., Langmead, O., Hardman-Mountford, N.J., Aiken, J., Boalch, G.T., Dando, P.R., Genner, M.J., Joint, I., Kendall, M.A., Halliday, N.C., Harris, R.P., Leaper, R., Mieszkowska, N., Pingree, R.D., Richardson, A.J., Sims, D.W., Smith, T., Walne, A.W., Hawkins, S.J., 2004. Long-Term Oceanographic and Ecological Research in the Western English Channel, in: Advances in Marine Biology. Academic Press, pp. 1-105. https://doi.org/10.1016/S0065-2881(04)47001-1

Sprung, M., 1984. Physiological energetics of mussel larvae (Mytilus edulis). I. Shell growth and biomass. Marine Ecology Progress Series 17, 283-293.

Thomas, Y., Bacher, C., 2018. Assessing the sensitivity of bivalve populations to global warming using an individual-based modelling approach. Glob Change Biol 24, 45814597. https://doi.org/10.1111/gcb.14402 
Thomas, Y., Pouvreau, S., Alunno-Bruscia, M., Barillé, L., Gohin, F., Bryère, P., Gernez, P., 2016. Global change and climate-driven invasion of the Pacific oyster (Crassostrea gigas) along European coasts: a bioenergetics modelling approach. J. Biogeogr. 43, 568-579. https://doi.org/10.1111/jbi.12665

van Vuuren, D.P., Edmonds, J., Kainuma, M., Riahi, K., Thomson, A., Hibbard, K., Hurtt, G.C., Kram, T., Krey, V., Lamarque, J.-F., Masui, T., Meinshausen, M., Nakicenovic, N., Smith, S.J., Rose, S.K., 2011. The representative concentration pathways: an overview. Climatic Change 109, 5. https://doi.org/10.1007/s10584-011-0148-z

Watson, J.R., Mitarai, S., Siegel, D.A., Caselle, J.E., Dong, C., McWilliams, J.C., 2010. Realized and potential larval connectivity in the Southern California Bight. Marine Ecology Progress Series 401, 31-48. https://doi.org/10.3354/meps08376

Wethey, D.S., Woodin, S.A., Hilbish, T.J., Jones, S.J., Lima, F.P., Brannock, P.M., 2011. Response of intertidal populations to climate: Effects of extreme events versus long term change. Journal of Experimental Marine Biology and Ecology 400, 132-144. https://doi.org/10.1016/j.jembe.2011.02.008

Yasuoka, N., Yusa, Y., 2016. Effects of size and gregariousness on individual sex in a natural population of the Pacific oyster Crassostrea gigas. Journal of Molluscan Studies 82, 485-491. https://doi.org/10.1093/mollus/eyw020

Yusa, Y., Breton, S., Hoeh, W.R., 2013. Population Genetics of Sex Determination in Mytilus Mussels: Reanalyses and a Model. Journal of Heredity 104, 380-385. https://doi.org/10.1093/jhered/est014

Zhang, X., Haidvogel, D., Munroe, D., Powell, E.N., Klinck, J., Mann, R., Castruccio, F.S., 2015. Modeling larval connectivity of the Atlantic surfclams within the Middle Atlantic Bight: Model development, larval dispersal and metapopulation connectivity. Estuarine, Coastal and Shelf Science 153, 38-53. https://doi.org/10.1016/j.ecss.2014.11.033

\section{SUPPLEMENTARY MATERIAL}

File 1/1: Model equations and parameters and additional results 